\title{
Three dimensional cyclonic turbulent flow structures at various geometries, inlet- outlet orientations and operating conditions
}

\author{
Pasymi $^{1,4}$, Y.W. Budhi ${ }^{2}$, A. Irawan ${ }^{3}$ and Y. Bindar ${ }^{1 *}$ \\ ${ }^{1}$ EPSChE Research Group, ${ }^{2}$ DDChEP Research Group \\ Department of Chemical Engineering, \\ Faculty of Industrial Technology, Institut Teknologi Bandung, Indonesia \\ ${ }^{3}$ Department of Chemical Engineering, Sultan Ageng Tirtayasa University, Indonesia \\ ${ }^{4}$ Department of Chemical Engineering, Faculty of Industrial Technology, \\ Bung Hatta University,Padang, Indonesia \\ *Email: ybybyb@fti.itb.ac.id
}

\begin{abstract}
Flow structure inside a chamber greatly determines the process performances. Therefore, the flow structure inside a chamber are often constructed in such a way as an effort to obtain equipment performances in accordance with the expectations. This study explored flow structure inside several chamber geometries and operating conditions. Three types of chamber, namely; GTC, DTC and TJC were set as the investigated chambers. The Computational Fluid Dynamics technique, supported by some experimental data from the literature, is used as an investigation method. The RANS based models, under AnsysFluent software were used in this numerical investigation. Simulation results revealed that the flow structures of GTC and DTC are predominantly created by spiral and vortex patterns. The vortex stabilizer diameter in the GTC affects the vortex pattern, velocity profile and pressure drop. The flow structure of DTC presents the most complex behavior. The flow structure inside TJC, in the case of unconfined outlet boundary, is characterized by the helical and wavy jet pattern. This structure is determined by the initial tangential intensity $\left(\mathrm{I}_{\mathrm{IT}}\right)$ and the inlet aspect ratio $\left(\mathrm{R}_{\mathrm{IA}}\right)$. The structures of vortex, helical, and wavy axial flow are properly constructed and visualized in this paper. There is no a turbulence model which is always superior to the other models, consistently. The standard k- $\varepsilon$ model exhibits the realistic and robust performances among all of investigatied cases.
\end{abstract}

Keywords: Cyclonic flows; flow structures; turbulence models; CFD technique; vortex pattern; inlet aspect ratio; initial tangential intensity.

\section{INTRODUCTION}

In many industrial equipments, the combinations of the tangential and axial flows are commonly build to govern the processes for functioning as they are expected. The equipments for separation, combustion, chemical reaction, and heat transfer will possibly apply different combinations and orientations of the tangential and axial flows. The flow structure in such equipments plays important roles in improving process performances. The investigation on the flow structures created by tangential-axial flow in various chamber geometries is presented. The chambers are grouped into Gravitational Tangential Chamber (GTC), Dominantly Tangential Chamber (DTC), and Tangential Jet Chamber (TJC). 
Effects of the geometry and operating condition on the flow structure in the GTC were explored by many authors [1, 2, 3, 4]. Hoekstra et al. [1] studied effect of the vortex finder diameter on the velocity profiles in the GTC. The smaller the vortex finder diameter, the smaller the vortex core size and the higher the maximum tangential velocity will be. Obermair et al. [2] conducted experiments and simulations to characterize the effect of dust outlet geometry on the separation efficiency in a GTC. They found that dust outlet geometry affects the flow profile and separation efficiency and concluded that cone with a downcomer tube is the best dust outlet geometry.

The effects of the swirl number (swirl intensity) on the flow structure in the GTC were investigated by Ko [3]. He stated that the swirl number is directly proporsional to the resirculation flow and separation efficiency of the GTC. Mathematical expression for swirl number of the GTC is given by equation (1). A recent study about GTC was conducted by Houben et al. [4]. A thin rod that is placed along the center of a GTC able to stabilize the vortex and to prevent it from precessing around the central axis.

$$
S_{N}=\frac{\pi D_{v f} D_{s}}{4 h \ell}
$$

The flow structure in the DTC was studied experimentally and numerically by Gupta and Kumar and Hreiz et al. [5, 6, 7]. Gupta and Kumar [5] found that flow structure in a DTC is consisted of two flow patterns. A helical pattern occurs near the wall and a vortex pattern located in the center of the chamber. Both flows have opposite directions. The inlet aspect ratio affects the precessing vortex core (PVC) in the DTC. Inlet aspect ratio $\left(\mathrm{R}_{\mathrm{IA}}\right)$ is defined as the width to thickness ratio of the tangential inlet cross sectional area $(l / h)$.

Hreiz et al. [6] investigated computationally the effects of the tangential inlet geometry on the flow pattern in the DTC. The rectangular shape of the tangential inlet produces better separation efficiency than the circular one. This claim is based on the fact that the rectangular shape reduces the vortex distortion and positively impacts to the separation efficiency. Hreiz et al. [7] also reported that the flow structure in the DTC is constructed by the vortex pattern at the center of the chamber. This pattern promotes a positive impact on the separation efficiency of DTC.

Chen et al. [8] investigated experimentally and numerically the effects of the initial tangential intensity $\left(\mathrm{I}_{\mathrm{IT}}\right)$ on the flow pattern in the TJC (unconfined swirl burner). They found that flow pattern is very sensitive to the $\mathrm{I}_{\mathrm{IT}}$ value and the tangential inlet number. The higher the $\mathrm{I}_{\mathrm{IT}}$ value and the tangential inlet number, the easier the axisymmetric flow to be formed. Initial tangential intensity is the ratio of the momentum flux through the tangential inlets to the total momentum flux through the test section. Mathematical formulation of $I_{I T}$ is given in equation (2), [8]. Nemoda et al. [9] stated that, the recirculation flow in the TJC is only formed at a high swirl number $\left(\mathrm{S}_{\mathrm{N}}>2.48\right)$. They also stated that the existence of the recirculation flow has a positive impact on the chemical conversion and the flame stability in the combustion process [9]. Another study of the effect of the outlet geometry on the fluid dynamics in the TJC was reported by Escudier et al. in [10]. Escudier et al. reported that the outlet contraction affects the velocity distribution in the TJC, especially in high swirl intensity.

$$
I_{I T}=\left(\frac{\dot{m}_{t}}{\dot{m}_{T}}\right)^{2}\left(\frac{A_{T}}{A_{t}}\right)^{2}
$$

The study of Escue and Cui [11], about the effect of swirl number, was concluded that the RNG k-e turbulence model properly works to predict the velocity profiles at low swirl number. For high swirl number, the RSM turbulence model works better to predict 
the velocity profiles [11].' Vazquez [12] conducted a simulation study on the effect of operating conditions on the flow structure in a TJC. The flow structure in a TJC is formed by the vortex pattern in the center and the spiral pattern near the wall [12]. An experiment and simulation work in the TJC was also reported by Bourgouin et al. [13]. The influence of the swirler geometry on the flow structures in the TJC is quantified. Their results indicate that the flow structure and the frequency of the PVC are extremely sensitive to the swirler geometries. The longer the blade of the swirler, the higher the angular and the axial velocities would be. This leads to the higher the frequency of the PVC [13].

Although, the cyclonic flow structures have been characterized by many researchers, howover, the detailed elaboration on the flow structures is required, especially at different influencing factors. The result will enhance the knowledge about the fluid flow structures. This paper has two main objectives, that are to evaluate the performance of turbulence model in several geometries dan operating conditions, and to characterize the flow structures in various chambers, inlet-outlet orientations and operating conditions. The chambers investigated here are GTC, DTC and TJC types. The results of the study will fill the scientific information gaps about the flow structure characteristics in the cyclonic chambers.

The flow structures of GTC and DTC are characterized by spiral and vortex patterns. Complex flow structures are produced by the DTC chamber. The helical and wavy jet flow structures inside the TJC chamber are exhibited. They are influenced by the inlet aspect ratio $\left(\mathrm{R}_{\mathrm{IA}}\right)$. The other important result for the studied cases is that there is no a turbulence model which is always superior to the other models, consistently. Interestingly, the standard $\mathrm{k}-\varepsilon$ turbulence model is considered to be the most robust turbulence model at all of investigated cases

\section{TURBULENCE MODELS AND CFD TECHNIQUES}

\section{Turbulence Models}

There are two kinds of turbulence models that are widely used by researchers in modeling the process, namely; RANS-based turbulence models and LES turbulence model. If the modeling is intended to design the equipment for process optimization, then the RANSbased turbulence models are the choice. Meanwhile, if the accuracy of the modeling results is prioritized, the LES turbulence model is the choice [14]. In this study, where the design process becomes the goal, the LES turbulence model is excluded.

Several comparison studies, on various RANS based turbulence model performances, have been published by various authors [15, 16, 17, 18, 19]. The conclusions are varied among the authors. But in general, the authors agreed that the RANS-based turbulence models are able to provide the adequate information for several design and operation purposes with a low computational effort. The feasibility, acceptability, and economic consideration become the evaluation criteria instead of high accuracy results only.

In the RANS based models, the formulations of the turbulent conservation equations come from the decomposed Navier-Stoke equations into RANS equations. For a clarity purpose, the cartesian coordinate of $\mathrm{x}, \mathrm{y}$, and $\mathrm{z}$ is used. The time average velocity components for $\mathrm{x}, \mathrm{y}$ and $\mathrm{z}$ directions are noted as $\bar{u}_{x}, \bar{u}_{y}$ and $\bar{u}_{z}$. Their velocity fluctuation components are written as $u_{x}{ }^{\prime}, u_{y}{ }^{\prime}$, and $u_{z}{ }^{\prime}$. The mass and momentum conservation equations for turbulent flow, known as RANS equations, are given by the equation below $[20,21]$. 


$$
\begin{aligned}
& \frac{\partial \rho}{\partial t}=\sum_{j=x}^{y, z}\left(\frac{\partial \rho \bar{u}_{j}}{\partial j}\right) \\
& \frac{\partial \rho \bar{u}_{i}}{\partial t}+\sum_{j=x}^{y, z} \frac{\partial \rho \bar{u}_{j} \bar{u}_{i}}{\partial j}=\frac{\partial \bar{p}}{\partial i}+\sum_{j=x}^{y, z} \frac{\partial}{\partial j}\left(\mu \frac{\partial \bar{u}_{i}}{\partial j}+\mu \frac{\partial \bar{u}_{j}}{\partial i}+\overline{\rho u_{\jmath}^{\prime} u_{\imath}{ }^{\prime}}\right)+\overline{\rho g_{\imath}} \\
& i=x, y, z
\end{aligned}
$$

The RANS equations contain six unknown turbulent stress terms. They are $\overline{\rho u_{x}{ }^{\prime} u_{x}{ }^{\prime}}$, $\overline{\rho u_{y}{ }^{\prime} u_{x}{ }^{\prime}}, \overline{\rho u_{z}{ }^{\prime} u_{x}{ }^{\prime}}, \overline{\rho u_{y}{ }^{\prime} u_{y}{ }^{\prime}}, \overline{\rho u_{z}{ }^{\prime} u_{y}{ }^{\prime}}$ dan $\overline{\rho u_{z}{ }^{\prime} u_{z}{ }^{\prime}}$. These turbulent stress terms are noted as $\mathrm{R}_{\mathrm{ij}}$. The essence of constructing the turbulence models lies on how to model these turbulent stress terms.

There are two ways of the strategy to model these stresses. The first is to model the turbulent stresses using the Boussinesq hypothesis. This way leads to eddy viscosity model (EVM). Two equations models are the most popular models of the EVM. The second is to use a second closure model approach. This second way arrives on the Reynolds Stress Model of the turbulent flow. Latter, it is known as a RSM turbulence model.

\section{Eddy Viscosity Turbulence models}

In this type of turbulence models, the turbulent stress terms are modeled with the Boussinesq approach by introducing a turbulent viscosity $\left(\mu_{t}\right)$. The Boussinesq's formulation for turbulent stress is given by equation (5). While the formulations of $\mu_{t}$ for each type of two equation models are given in equation (6) and (7). Variables $k, \varepsilon$ and $\omega$ of these equations are turbulent kinetic energy, dissipation rate of turbulent kinetic energy and specific dissipation rate, respectively.

$$
\begin{gathered}
\tau_{t}=\overline{\rho u_{\imath}^{\prime} u_{\jmath}^{\prime}}=-\mu_{t}\left[\frac{\partial \bar{u}_{i}}{\partial x_{j}}+\frac{\partial \bar{u}_{j}}{\partial x_{i}}\right] \\
\mu_{t}=C_{\mu} f_{\mu} \rho \frac{k^{2}}{\varepsilon} \\
\mu_{t}=\alpha^{*} \rho \frac{k}{\omega}
\end{gathered}
$$

Variable $f_{\mu}$ in equation (6) is a dumping fuction. The formulation of this function will distinguish between standard, RNG and realizable k- $\varepsilon$ models. For the standard k- $\varepsilon$ model, $f_{\mu}=1$, then the formulation of $\mu_{t}$ is simplified as equation (8).

$$
\mu_{t}=C_{\mu} \rho \frac{k^{2}}{\varepsilon}
$$

By entering the above equations into the RANS equations, the mass and momentum conservation equations for the turbulence flow will arrive to equation (9) - (12). While, the conservation equations for $k, \varepsilon$ and $\omega$ are given in equations (13) - (15). Each set of turbulent models for $k-\varepsilon$ or $k$ - $\omega$ models, has 6 conservation equations to be solved simultaneously. Equations (9) - (14) are set for $k-\varepsilon$ models and equations (9) - (13) and (15) are set for $k-\omega$ model [21]. 


$$
\begin{aligned}
& \frac{\partial \rho}{\partial t}=\sum_{j=x}^{y, z}\left(\frac{\partial \rho \bar{u}_{j}}{\partial j}\right) \\
& \frac{\partial \rho \bar{u}_{x}}{\partial t}+\sum_{j=x}^{y, z}\left(u_{j} \frac{\partial \rho \bar{u}_{x}}{\partial j}\right)=-\frac{\partial \bar{p}}{\partial x}+\sum_{j=x}^{y, z} \frac{\partial}{\partial j}\left[\mu_{\mathrm{eff}} \frac{\partial \bar{u}_{x}}{\partial j}\right]+\rho g_{x} \\
& \frac{\partial \rho \bar{u}_{y}}{\partial t}+\sum_{j=x}^{y, z}\left(u_{j} \frac{\partial \rho \bar{u}_{y}}{\partial j}\right)=-\frac{\partial \bar{p}}{\partial y}+\sum_{j=x}^{y, z} \frac{\partial}{\partial j}\left[\mu_{\mathrm{eff}} \frac{\partial \bar{u}_{y}}{\partial j}\right]+\rho g_{y} \\
& \frac{\partial \rho \bar{u}_{z}}{\partial t}+\sum_{j=x}^{y, z}\left(u_{j} \frac{\partial \rho \bar{u}_{z}}{\partial j}\right)=-\frac{\partial \bar{p}}{\partial z}+\sum_{j=x}^{y, z} \frac{\partial}{\partial j}\left[\mu_{\mathrm{eff}} \frac{\partial \bar{u}_{z}}{\partial j}\right]+\rho g_{z} \\
& \rho \frac{\partial k}{\partial t}+\sum_{j=x}^{y, z} \rho \bar{u}_{j} \frac{\partial k}{\partial j}=\sum_{j=x}^{y, z} \frac{\partial}{\partial j}\left[\frac{\mu_{\mathrm{eff}}}{\sigma_{\mathrm{k}}} \frac{\partial k}{\partial j}\right]+G_{\mathrm{k}}-\rho \varepsilon \\
& \rho \frac{\partial \varepsilon}{\partial t}+\sum_{j=x}^{y, z} \rho \bar{u}_{j} \frac{\partial \varepsilon}{\partial j}=\sum_{j=x}^{y, z} \frac{\partial}{\partial j}\left[\frac{\mu_{\mathrm{eff}}}{\sigma_{\varepsilon}} \frac{\partial \varepsilon}{\partial j}\right]+C_{\varepsilon 1} \frac{\varepsilon}{k} G_{k}-C_{\varepsilon 2} \rho \frac{\varepsilon^{2}}{k} \\
& \rho \frac{\partial \omega}{\partial t}+\sum_{j=x}^{y, z} \rho \bar{u}_{j} \frac{\partial \omega}{\partial j}=\sum_{j=x}^{y, z} \frac{\partial}{\partial j}\left[\frac{\mu_{e f f}}{\sigma_{\omega}} \frac{\partial \omega}{\partial j}\right]+\alpha \frac{\omega}{k} P_{k} \\
& -\rho\left[\frac{0.267+\{0.125 \rho k /(\mu \omega)\}^{4}}{1+\{0.125 \rho k /(\mu \omega)\}^{4}}\right] f_{\omega} \omega^{2}
\end{aligned}
$$

Where

$$
\mu_{e f f}=\mu+\mu_{t}
$$

\section{Second Closure Models}

In the second closure models, each turbulent stress equation $\left(R_{i j}\right)$ for a non-bouyant flow is constructed by the terms of time derivative, convection $C_{i j}$, diffusion $D_{i j}$, stress production $P_{i j}$, pressure strain $\phi_{i j}$, and dissipation $\varepsilon_{i j}$. The indexs $i, j, l$ and $m$ identify $x$, $y$ and $z$ components. The development of second closure model refers to the works of Launder et al. [22, 23]. The turbulent stress formulation for this model is expressed by equation (17).

$$
\frac{\partial R_{i j}}{\partial t}+C_{i j}=D_{T, i j}+D_{L, i j}+P_{i j}+\phi_{i j}-\varepsilon_{i j}
$$

All terms in the above equation are defined and modelled for three dimensional flows in $\mathrm{x}, \mathrm{y}$, and $\mathrm{z}$ directions by the following equations.

$$
\begin{aligned}
& C_{i j}=\sum_{l}^{x, y, z} \bar{u}_{l} \frac{\partial R_{i j}}{\partial l} \\
& D_{T, i j}=\sum_{l}^{x, y, z} \frac{\partial}{\partial l}\left[\frac{\mu_{t}}{\rho \sigma_{R}} \frac{\partial R_{i j}}{\partial l}\right] \\
& D_{L, i j}=\sum_{l}^{x, y, z} \frac{\partial}{\partial l}\left[\mu \frac{\partial R_{i j}}{\partial l}\right] \\
& P_{i j}=-\sum_{l}^{x, y, z}\left(R_{l i} \frac{\partial \bar{u}_{j}}{\partial l}+R_{l j} \frac{\partial \bar{u}_{i}}{\partial l}\right) \\
& \varepsilon_{i j}=\frac{2}{3} \delta_{i j} \rho \varepsilon
\end{aligned}
$$




$$
\begin{aligned}
\phi_{i j}= & \phi_{i j, 1}+\phi_{i j, 2}+\phi_{i j, w} \\
\phi_{i j, 1}= & C_{1} \frac{\varepsilon}{k}\left(R_{i j}-\frac{2}{3} \delta_{i j} \rho k\right) \\
\phi_{i j, 2}= & -C_{2}\left\{P_{i j}-C_{i j}-\frac{2}{3} \delta_{i j} 0.5\left(P_{m m}-C_{m m}\right)\right\} \\
\phi_{i j, w}= & C_{1}{ }^{\prime} \frac{\varepsilon}{k} \frac{1}{\rho}\left\{R_{l m} n_{l} n_{m} \delta_{i j}-\frac{3}{2} R_{i l} n_{j} n_{l}-\frac{3}{2} R_{j l} n_{i} n_{l}\right\} C_{l} \frac{k^{3 / 2}}{\varepsilon d}+ \\
& C_{2}{ }^{\prime} \frac{\varepsilon}{k}\left\{\phi_{k m, 2} n_{k} n_{m} \delta_{i j}-\frac{3}{2} \phi_{i k, 2} n_{j} n_{k}-\right. \\
\frac{3}{2} \phi_{j k, 2} & \left.n_{i} n_{k}\right\} C_{l} \frac{k^{3 / 2}}{\varepsilon d}
\end{aligned}
$$

For closure the RSM model, equations (13) and (14) are still employed to obtain the values of $k$ and $\varepsilon$. Totally, the RSM model has 12 conservation equations. They are equations (5) - (14) and 6 equations from the expansion of equation (6). These equations must be solved simultaneously. That is way, the RSM model requires much larger computational effort than the $k-\varepsilon$ or the $k$ - $\omega$ turbulence models.

The kinetic energy production rate $\left(P_{k}\right)$ is directly computed from the turbulent stress solutions as shown by equation (27), while the turbulent viscosity $\mu_{\mathrm{t}}$ is evaluated from equation (8) with $C_{\mu}=0.09$. The values of the constants are $C_{1}=1.8, C_{2}=0.6$, $C_{1}^{\prime}=0.5, C_{2}^{\prime}=0.3, C_{l}=0.392$, and $\sigma_{R}=0.82$. Variables $n_{i}, n_{j}, n_{k}, n_{l}$, and $n_{m}$ are normal unit vectors of a surface. The parameter $d$ is the distance from the nearest grid point to the wall.

$$
P_{k}=\frac{1}{2} \sum_{j}^{x, y, z} P_{j j}
$$

\section{CFD Technique}

The flow variables in the above equations are generalized as $\Phi$ variables. The model equations for these variables are formed by partial differential equations with transient, convection, diffusion, and source terms. The diffusional coefficients are introduced as $\Gamma_{\Phi}$. For a scalar variable, the model equation is expressed in a general form as follow [24].

$$
\rho \frac{\partial \Phi}{\partial t}+\sum_{l}^{x, y, z} \rho \bar{u}_{l} \frac{\partial \Phi}{\partial l}=\sum_{l}^{x, y, z} \frac{\partial}{\partial l}\left[\Gamma_{\Phi} \frac{\partial \Phi}{\partial l}\right]+S_{\Phi}
$$

Variable $S_{\Phi}$ is known as a source term for the variable $\Phi$. The general equation for the momentum variables $\bar{u}_{x}, \bar{u}_{y}$ and $\bar{u}_{z}$ is similar to equation (28) with the additional pressure gradient $(-\nabla p)$ on the right hand side of the equation (28).

The model equations are solved numerically within the geometry domain. The geometry is meshed into $\mathrm{N}_{\mathrm{v}}$ number of finite control volumes, including the boundary control volumes. The volume of a control volume is indicated by $\Delta V_{i j l}$ with the side sizes of $\Delta x_{i j l}, \Delta y_{i j l}$ and $\Delta z_{i j l}$. The individual control volume has a grid point that may be located at the center of the control volume. The grid point is indexed by ijl. The computed values of the variables are associated with the values at the grid point $\Phi_{\mathrm{ijl}}$. Each control volume has $N_{f i j l}$ enclosing faces. The values of $\Phi$ on a face are quantified as $\Phi_{f i j l}$.

Each equation model of equation (28) is integrated on the individual control volume. This involves the grid point and the face values. The velocity on a face of a control volume $\Delta \mathrm{V}_{\mathrm{ijl}}$ is indicated by $\bar{u}_{f i j l}$, that is always perpendicular to the face with the area of $A_{\text {fijl }}$. The diffusional terms as the gradients are evaluated at the faces and are 
shortened as $\nabla \Phi_{f i j l}$. The approached momentum equation over $\Delta V_{i j l}$ is produced as below.

$$
\begin{gathered}
\rho_{i j l} \frac{\Delta \Phi_{i j l}}{\Delta t} \Delta V_{i j l}+\sum_{f}^{N_{f i j l}}\left(\rho_{f i j l} \bar{u}_{f i j l} A_{f i j l} \Phi_{f i j l}\right)= \\
\sum_{f}^{N_{f i j l}}\left(\Gamma_{f i j l} \nabla \Phi_{f i j l} A_{f i j l}\right)-\sum_{f}^{N_{f i j l}}\left(\mathrm{p}_{f i j k} A_{f i j l}\right)+S_{\Phi \mathrm{ijl}} \Delta V_{i j l}
\end{gathered}
$$

For a scalar variable, the approached equation is similarly obtained to equation (29) by omitting $\sum_{\mathrm{f}}^{\mathrm{N}_{\mathrm{fijl}}}\left(\mathrm{p}_{\mathrm{fijl}} \mathrm{A}_{\mathrm{fijl}}\right)$ term. The transient term and the diffusional gradient of the variables are expanded from the grid values by discretization using a finite difference, a finite element or a combination method. They are all well described in many text books [20, 21, 24, 25]. The time discretization involves an explicit or implicit approach with first or second order discretization. The diffusional gradient is based on the spatial discretization concept. The spatial schemes are constructed as a first order, second order or power law approach. The spatial schemes are shown in Table 1.

Table 1. Spatial schemes for each variable

\begin{tabular}{lll}
\hline No. & Variable & Scheme \\
\hline 1 & Pressure, $p$ & Second Order and PRESTO \\
2 & Momentums, $u_{x}, u_{y}, u_{z}$ & Second Order Upwind and QUICK \\
3 & Turbulent kinetic energy, $k$ & First Order Upwind and QUICK \\
4 & Turbulent dissipation rate, $\varepsilon$ & First Order Upwind and QUICK \\
\hline
\end{tabular}

Equation (29) is then transformed into a linear algebraic equation for each variable at each grid point of the control volume. Each control volume has $N_{i j k, n b}$ enclosing neighbor control volumes. The variable value for the neighbor control volume is given by $\Phi_{\mathrm{ijk}, \mathrm{nb}}$. Then, this linear algebraic equation is expressed as follow.

$$
a_{P, i j l} \Phi_{i j l}=\sum_{n b}^{N_{i j l n b}} a_{i j l, n b} \Phi_{i j l, n b}+b_{i j l}
$$

The coefficient $a_{P, i j k}$ is a linearized coefficient for $\Phi_{\mathrm{ijk}}$ that is evaluated as a function of the grid sizes $\left(\Delta x_{i j l}, \Delta y_{i j l}\right.$ and $\left.\Delta z_{i j l}\right)$, the fluid properties, the diffusional coefficients and the computed velocities from the previous iteration. The coefficients $\mathrm{a}_{\mathrm{ijk}, \mathrm{nb}}$ are linearized coefficients that are associated to the $\Phi_{\mathrm{ijk}, \mathrm{nb}}$ values. These are evaluated with the same way with $a_{P, i j k}$. The term $b_{i j k}$ is the contribution of the source term to the conservation equation of the variable $\Phi_{\mathrm{ijk}}$.

Each algebraic equation generates $N_{v} x N_{v}$ matrix coefficient that relates to $N_{v}$ spatial locations of the computed variable. Solving such this size of the matrix coefficient to obtain the values of the variables requires a robust matrix solver and a powerful computer facility. The multigrid solver becomes the standard method solving such this size matrix coefficient. The computing work must be done iteratively to avoid the direct matrix inversion.

The pressure field in the momentum equations is solved from a linearized algebraic pressure correction $\left(p^{\prime}\right)$ equation that is obtained by manipulation of the continuity equation [24]. This leads to a pressure-based segregated algorithm for solving the whole equation variables above. The pressure values at faces are computed using the 
interpolation scheme of Linear, Second Order or PRESTO (Pressure Staggering Option). The pressure-based segregated algorithm starts with guessed values, continues to update the fluid properties, solves the momentum equations one another with recent updated values, solves the pressure correction with recent velocity values, corrects pressure and velocity fields, solves all scalar variables with recent velocity field, updates the source term, checks for convergence of the equations and continues the iterations until the converged solution. Such this algorithm can be arranged in a different way. Some available algorithms are SIMPLE, SIMPLEC and PISO. The SIMPLE algorithm is commonly used to solve the pressure-velocity coupling equation system.

\section{INVESTIGATION METHODOLOGY}

The importance of physical experiments in studying cyclone flow patterns is undeniable and the results are indisputable. However, physical experiments require large resources and become very expensive, while the measured data obtained ar very limited. The Computational Fluid Dynamic (CFD) techniques have often been used extensively to supplement the experimental data. The CFD technique is able to produce detailed data with more efficient resources, larger scope of study, designs that can be repeated and optimal results [26]. The use of CFD techniques in flow structures investigation has been reported by several researchers [27, 28, 29]. The CFD software used in this study is Ansys-Fluent, which was widely used by academics, researchers and industry practitioners.

The CFD performance is influenced by computational (CFD) variables and by the turbulence models used. Therefore, before begining a simulation, the sensitivity of these CFD variables to the simulation results must be evaluated first. After that, a suitable turbulent model must be found. The last step of this study is to explore in depth the effects of certain variables on the flow structure in several chambers.

\section{Sensitivity Evaluation of CFD Variables}

There are several CFD variables which are evaluated their sensitivity here. They are mesh size, mesh type, wall function, boundary condition and scheme type. The sensitivity evaluations are conducted using experimental data of Hoekstra et al. [1], Gupta and Kumar [5] and Chen et al. [8]. These sensitivity evaluations commonly use the powerful and simple turbulence model.

\section{Performance Evaluations of Turbulence models}

There are five turbulence models that are evaluated their performances. Those are standard k- $\varepsilon$, standard k- $\omega$, RNG k- $\varepsilon$, Realizable k- $\varepsilon$, and RSM model. The performance evaluation was done by comparing the modelling results with the corresponding experimental data from the literatures. There are three chamber geometries used as the object of the model performance evaluation, namely: GTC, DTC, and TJC. A part of the Hoekstra's [1], Gupta and Kumar's [5], and Chen's [8] data were used to validate the turbulence model performances. Three dimensional geometries of the three chambers were constructed and shown in Figure 1. 


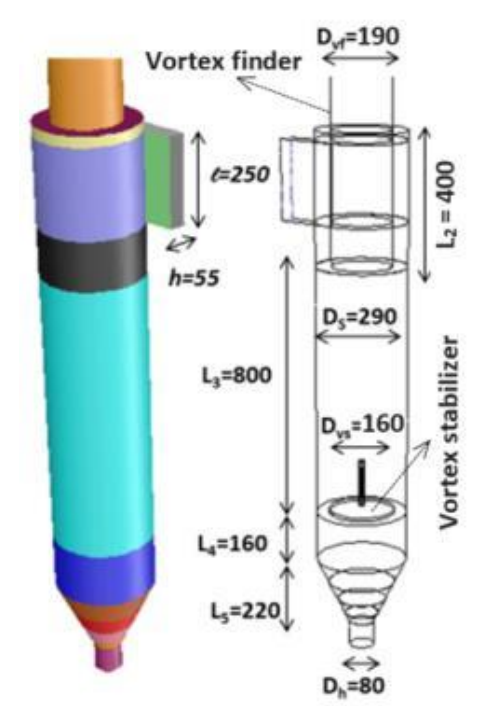

a). Gravitational Tangential Chamber, Hoekstra et al. (1999)

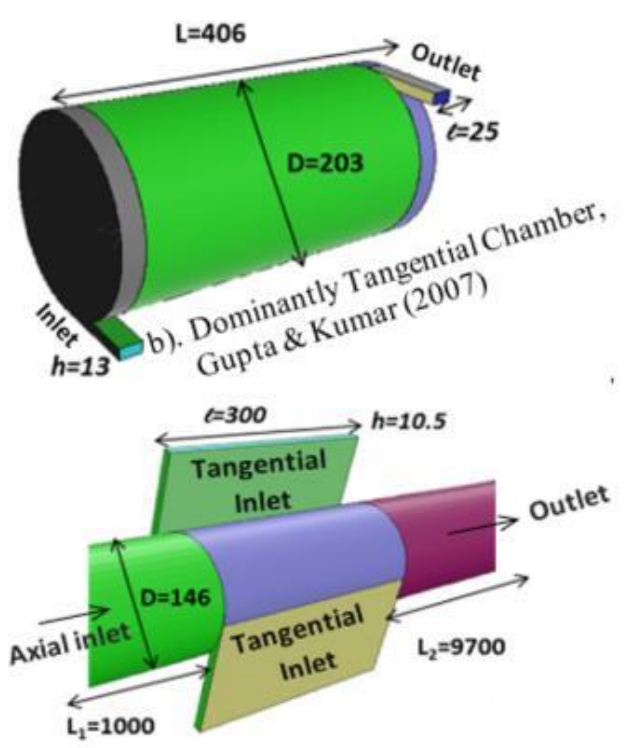

c). Tangential Jet Chamber, Chen et al. (1999)

Figure 1. Typical geometries of The GTC, DTC and TJC (all dimensions in mm)

\section{Exploration of the Certain Variables on the Flow Structure}

Exploration of the flow structure is carried out on the three chamber geometries mentioned above, by looking for the gaps from the studies that have been conducted before. The results of this study are expected to enrich the information and knowledge about the flow structure of the three chambers.

\section{Gaps of the Flow Structure Studies in GTC}

The following is the list of studies about the effect of geometry and operating condition on the GTC performances. The investigated variables and the results are summarized in Table 2.

Table 2. Investigation list about GTC Performances

\begin{tabular}{|c|c|c|}
\hline Researcher & Investigated variable & Result \\
\hline $\begin{array}{l}\text { Hoekstra } \\
\text { et al.[1] }\end{array}$ & $\begin{array}{l}\text { Vortex finder diameter, } \\
\text { swirl number } \begin{array}{r}\text { and } \\
\text { turbulence }\end{array} \text { model } \\
\text { performance }\end{array}$ & $\begin{array}{l}\text { Reynolds stress model are sligtly better in } \\
\text { predicting flow structure in GTC than the k- } \\
\varepsilon \text { models. Vortex finder diameter is directly } \\
\text { proporsional to the vortex core size. }\end{array}$ \\
\hline $\begin{array}{l}\text { Obermair } \\
\text { et al. [2] }\end{array}$ & Dust outlet geometry & $\begin{array}{l}\text { Dust outlet geometry affected the flow } \\
\text { stucture and separation efficiency. The cone } \\
\text { with a downcomer tube showed the best } \\
\text { dust outlet geometry. }\end{array}$ \\
\hline Ko [3] & Swirl number & $\begin{array}{l}\text { Swirl number is directly proporsional to the } \\
\text { resirculation flow and separation efficiency }\end{array}$ \\
\hline $\begin{array}{l}\text { Houben et } \\
\text { al. [4] }\end{array}$ & Vortex stabilizer & $\begin{array}{l}\text { A thin rod (vortex stabilizer) placed along } \\
\text { the center of a GTC can stabilize the vortex } \\
\text { and able to prevent the vortex core from } \\
\text { precessing around the central of chamber }\end{array}$ \\
\hline
\end{tabular}


In the experiment of Hoekstra [1], the GTC is equiped by a vortex stabilizer at the bottom of the chamber, as can be seen in

Figure 1a. This stabilizer is thought to have an effect on the flow structure in the GTC, but there is no Hoekstra discussion related to this variable. Therefore, the influence of the vortex stabilizer on the flow structure in the GTC will be numerically explored in detail. The effect of inlet aspect ratio on the flow structure in the GTC will also be investigated here.

\section{Gaps of Flow Structure Studies in DTC}

The studies by various authors about the effect of geometry and operating condition on the performance of DTC are listed in Table 3. There is an important aspects missing from the their studies, namely the influence of the inlet-outlet orientation on the flow structure. The inlet-outlet orientation of the DTC can be varied as given in Figure 2. Here, the effect of inlet-outlet orientation on the flow structure in the DTC are explored extensively through the numerical investigation. The typical geometry of DTC which is investigated refered to the Figure $1 b$.

Table 3. List of studies about DTC performances

\begin{tabular}{|c|c|c|}
\hline Author & Investigated variable & Result \\
\hline $\begin{array}{l}\text { Gupta and } \\
\text { Kumar [5] }\end{array}$ & Inlet aspect ratio & $\begin{array}{l}\text { RNG k- } \varepsilon \text { is able to predict flow structure } \\
\text { in the DTC, adequately. The flow } \\
\text { structure in the DTC consist of helical } \\
\text { patern near the wall and vortex pattern at } \\
\text { the center. The vortex is always } \\
\text { precessing around the center of } \\
\text { chamber. The precessing vortex core is } \\
\text { influenced by the Inlet aspect ratio. }\end{array}$ \\
\hline Hreiz et al. [6] & $\begin{array}{l}\text { Tangential inlet } \\
\text { geometry }\end{array}$ & $\begin{array}{l}\text { The rectangular shape can reduce the } \\
\text { vortex distortion and increase separation } \\
\text { efficiency. }\end{array}$ \\
\hline Hreiz et al. [7] & $\begin{array}{l}\text { Swirl intensity and } \\
\text { number of tangential } \\
\text { inlet }\end{array}$ & $\begin{array}{l}\text { Vortex pattern that is directly } \\
\text { influenced to the flow swirl intensity and } \\
\text { has positive impact to the separation } \\
\text { efficiency. }\end{array}$ \\
\hline
\end{tabular}

\section{Gaps of the Flow Structure Studies in TJC}

It is so many studies related to the TJC performances as listed in Table 4. The TJC is often used either as a mixing chamber, as a combustion chamber or as a heat transfer equipment. Although, the effect of initial tangential intensity on the flow structure has been studied by Chen et al [8], but it is still needed to be explored more widely. The effect of inlet aspect ratio on the flow structure in TJC is the one to be explored intensively. The typical TJC geometry investigated here is refered to the Figure 1c. 
Table 4. Investigation list about TJC Performances

\begin{tabular}{|c|c|c|}
\hline Author & Investigated variable & Result \\
\hline $\begin{array}{l}\text { Chen et al. } \\
{[8]}\end{array}$ & $\begin{array}{l}\text { Initial tangential intensity, } \\
\text { tangential inlet number }\end{array}$ & $\begin{array}{l}\text { The flow pattern in the TJC is very } \\
\text { sensitive to the } \mathrm{I}_{\mathrm{TI}} \text { value and the } \\
\text { tangential inlet number. }\end{array}$ \\
\hline $\begin{array}{l}\text { Nemoda et } \\
\text { al. [9] }\end{array}$ & Swirl number, & $\begin{array}{l}\text { Recirculation flow is only formed at high } \\
\text { swirl number }\left(S_{N}>2.48\right) \text {. }\end{array}$ \\
\hline $\begin{array}{l}\text { Escudier et } \\
\text { al. [10] }\end{array}$ & Outlet geometry & $\begin{array}{l}\text { Outlet contraction will affect the velocity } \\
\text { distribution in the TJC. }\end{array}$ \\
\hline $\begin{array}{l}\text { Escue and } \\
\text { Cui [11] }\end{array}$ & Swirl number & $\begin{array}{l}\text { At low swirl number, the RNG k- } \varepsilon \text { and } \\
\text { RSM turbulence model are suitable to } \\
\text { predict the the velocity profile in TJC. } \\
\text { But for high swirl number, RSM model } \\
\text { has better prediction than the RNG k- } \varepsilon \\
\text { model }\end{array}$ \\
\hline $\begin{array}{l}\text { Vazquez } \\
\text { [12] }\end{array}$ & $\begin{array}{l}\text { Turbulence } \\
\text { performance, swirl number } \\
\text { and outlet boundary condition }\end{array}$ & $\begin{array}{l}\text { RSM turbulence model is not always } \\
\text { superior to the k- } \varepsilon \text { model. Outlet } \\
\text { boundary condition of the TJC greatly } \\
\text { determines the presence of the } \\
\text { recirculation flow. }\end{array}$ \\
\hline $\begin{array}{l}\text { Bourguoin } \\
\text { et al. [13] }\end{array}$ & Swirler geometry & $\begin{array}{l}\text { The longer the blade of the swirler, the } \\
\text { higher the angular and the axial velocities } \\
\text { are. This leads to the higher the frequency } \\
\text { of the PVC. }\end{array}$ \\
\hline
\end{tabular}

There are several independent variables that are numerically explorable for their influences on the flow structure of the three typical geometries. The descriptions of the independent variables for each typical of chamber are summarized in Table 5.

Table 5. Variables in CFD simulations

\begin{tabular}{|c|c|c|c|}
\hline No. & Chamber & Independent Variable & Variations \\
\hline 1 & GTC & $\begin{array}{l}\text { Vortex stabilizer diameter, } \mathrm{D}_{\mathrm{vs}}(\mathrm{m}) \text {; } \\
\text { Inlet aspect ratio, } \mathrm{R}_{\mathrm{IA}} \text { (dimensionless ) }\end{array}$ & $\begin{array}{l}(0,0.16,0.19,0.21) \\
(8.6,5.74 .5)\end{array}$ \\
\hline 2 & DTC & Inlet-outlet orientation & Io1 to Io12 in Figure 2. \\
\hline 3 & TJC & $\begin{array}{l}\text { Inlet aspect ratio, } \mathrm{R}_{\mathrm{IA}} \text { (dimensionless); } \\
\text { Initial tangential intensity, } \\
\text { (dimensionless) }\end{array}$ & $\begin{array}{l}(13.6,15,28.5,40) \\
(1,6,9,13,22,44)\end{array}$ \\
\hline
\end{tabular}




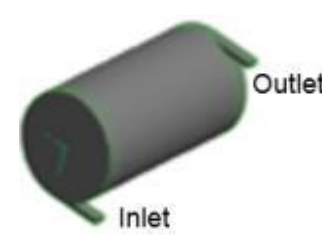

(Io1)

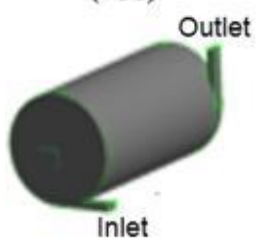

(Io5)

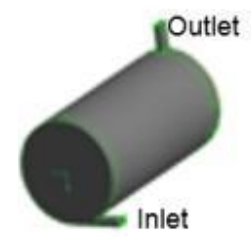

(I09)

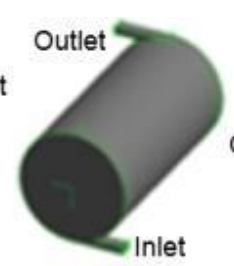

$\left(\mathrm{I}_{\mathrm{O} 2}\right)$

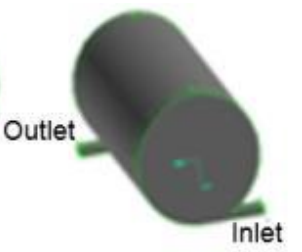

( $\left.\mathrm{I}_{\mathrm{O} 3}\right)$

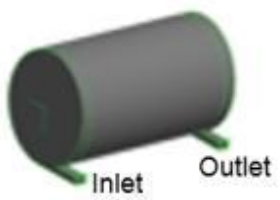

(I04)
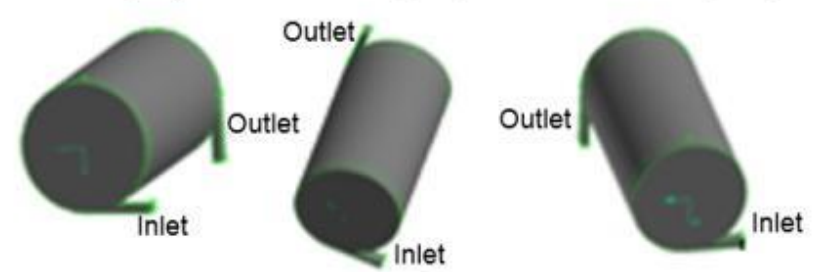

(Io6)

( $\left.\mathrm{Io}_{0}\right)$

(Io8)
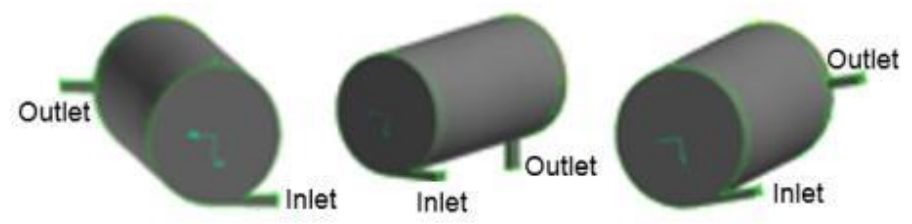

(Io10)

(Io11)

(Io12)

Figure 2 Inlet-outlet orientations for the DTC geometry

\section{RESULTS AND DISCUSSION}

\section{CFD Parametric Sensitivity Analysis}

There are several CFD parameters that have been analyzed their sensitivity on the simulation results. They are mesh size and type, boundary layer, wall function, pressurevelocity coupling scheme and spatial discretization scheme. Among the numerical variables analyzed, the mesh size was significantly found to affect the simulation result, as depicted by Figure 3. A too large mesh size tends to produce the simulation results to be inaccurate. However, a small mesh size requires an enormous computational effort. Therefore, all of the next CFD computations are already based on this optimized mesh size. The optimized mesh size was identified in the range size of $2.5-7.5 \%$ of the chamber diameter.

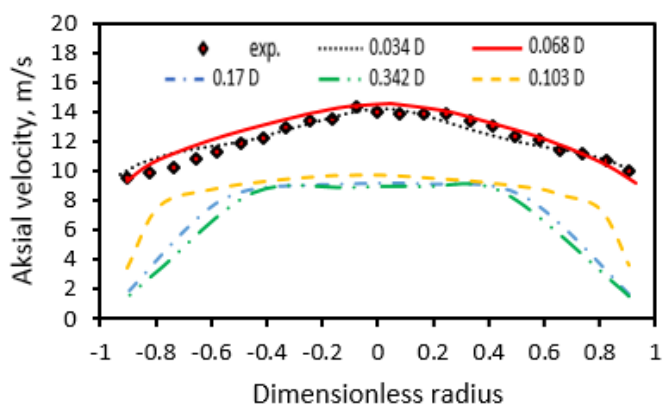

(a) Axial velocity

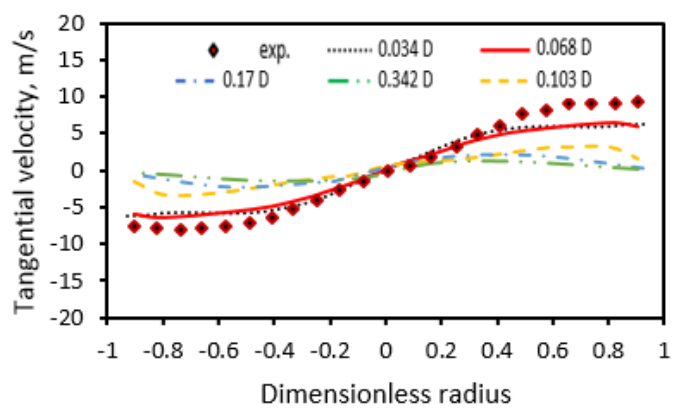

(b) Tangential velocity

Figure 3. Sensitivity of mesh size to the simulation results in TJC using standard k- $\varepsilon$ model 
In addition, for the case of GTC, spatial discretization scheme was also found to have significant effect to the velocity profile, especially to the axial velocity profile. Almost all of the turbulence models failed to capture the axial velocity profile in the center of the chamber, except RSM. RSM model, with PRESTO spatial discretization scheme, performs a better prediction in the axial velocity profile inside the GTC, as shown in Figure 4b. In the case of DTC and TJC, the spatial discretization schemes do not affect the simulation results. The results are not to be sensitive to the other numerical variables.

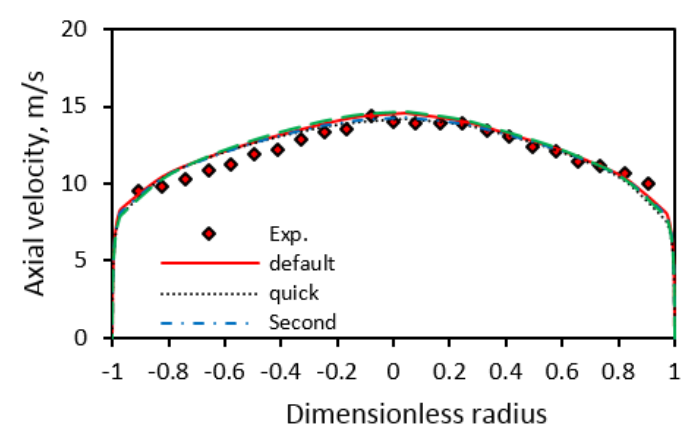

(a) Axial velocity in TJC

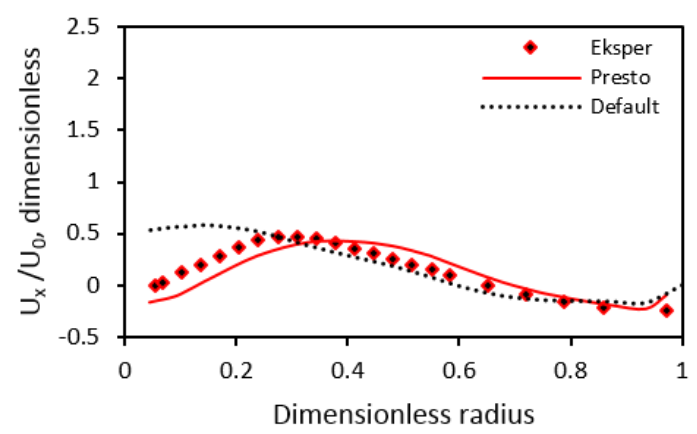

(b) Axial velocity in GTC

Figure 4. Sensitivity of spatial discretiation scheme to the simulation result, (a) using standard k- $\varepsilon$ model in the TJC and (b) using a RSM turbulence model in the GTC

\section{Performance evaluations of turbulence models in specific chambers Gravitational Tangential Chamber}

The validation data used in this study are the axial and tangential velocity profiles which are extracted from Hoekstra et al. [1], for the case of high swirl flow $\left(\mathrm{S}_{\mathrm{N}} 3.1\right)$ and vortex finder diameter of $0.19 \mathrm{~m}$. The fluid velocities were measured by laser doppler velocimetry and recorded at the axial distance of $0.65 \mathrm{~m}$ from the chamber inlet. The comparisons of the axial and tangential velocity profiles between the simulation results and the experimental data are given in Figure 5.

Except for the RSM model, other turbulence models failed to predict the trends of the axial velocity profile in the center region of the chamber, Figure 5a. The RSM turbulence model could follow the experimental data trend for the axial velocity profile quite well. Quantitatively, the predictions of RSM model are deviated from the experimental data; $25 \%$ for axial velocity $(60 \%$ at $r \leq 0.3 \mathrm{R}$ and $10 \% \mathrm{r}>0.3 \mathrm{R})$ and $22 \%$ for tangential velocity. These deviations are more or less the same as the modeling results conducted by Hoekstra et al [1].

This can be analyzed from the highly anisotropic flow at the center of the chamber. This relates to the existence of the strong vortex structure flow at the center of the chamber. However, the trends for the tangential velocity profiles are well captured by all turbulence models, Figure 5b. These results are in line with the Talbi's findings [30] for the similar case in which both RSM and k- $\varepsilon$ turbulence models can follow the trends of the tangential velocity profiles, well. The RSM model is only superior in predicting the tangential velocity peak at a narrow layer from $0.27 \mathrm{R}$ to $0.45 \mathrm{R}$ [30].

The inability of the $k-\varepsilon$ and $k-\omega$ models in predicting the strong anisotropic flows are due to the models themselves. The models are especially formulated for the isotropic conditions [31]. Although, there are modifications for the standard k- $\varepsilon$ model, such as RNG k- $\varepsilon$ and Realizable k- $\varepsilon$ model, the results from these models are still unsatisfactory to predict strong anisotropic flows, as reported in $[2,11]$. The RSM models predicted 
properly and accurately the velocity profiles along the radius of the chamber, both axially and tangentially. This is due to the RSM model are formulated by involving the anisotropic turbulent conditions [32]. However, in a very strong anisotropic flow condition, the RSM predictions begin to be inadequate for the velocity profiles especially at the center region of the chamber [3].

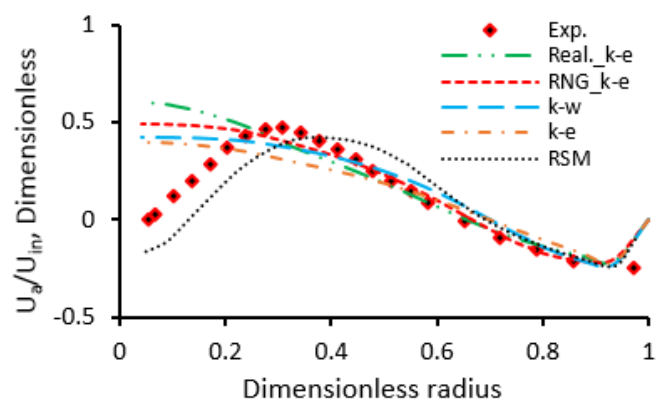

(a) Axial velocity

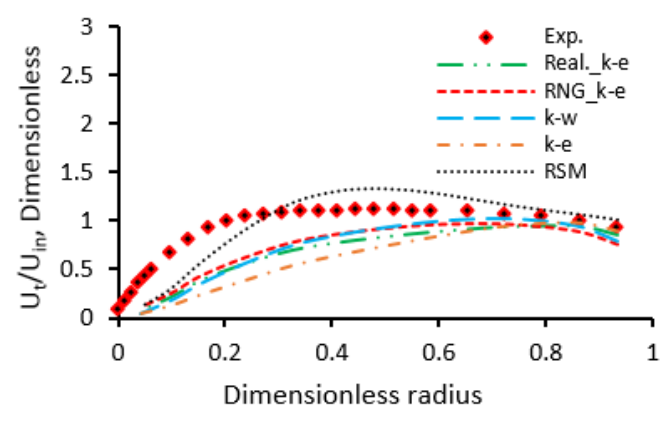

(b) Tangential velocity

Figure 5. Axial and tangential velocity profiles in the GTC (at $\mathrm{z}=0.65 \mathrm{~m}$ ).

It is true that predictions by the RSM turbulence model are more proper and more accurate. However, the effort of obtaining the converged solution using RSM turbulence model is not easy. The more complex geometry and phenomena involved, the more difficult the computational works that must be faced. The effect of the inaccurate axial velocity profile on the global process performances of the chamber, like the solid separation efficiency, can be answered by including the solid separation model. If the less accurate velocity profiles do not affect the solid separation efficiency significantly, then the use of affordable turbulence model, such as a standard k- $\varepsilon$ turbulence model is justified.

\section{Dominantly Tangential Chamber}

Another evaluation of the turbulence models performances was conducted in the DTC, Figure 1b. In this case, the validation data were extracted from Gupta and Kumar [5]. The comparisons are presented for the inlet aspect ratio of 2 and the Reynolds number of 18000. The observation points of velocity data are taken from the angle positions of $0^{0}$ and $90^{\circ}$ and the axial position of $0.152 \mathrm{~m}$ from the inlet. These velocities comparisons are shown by Figure 6.

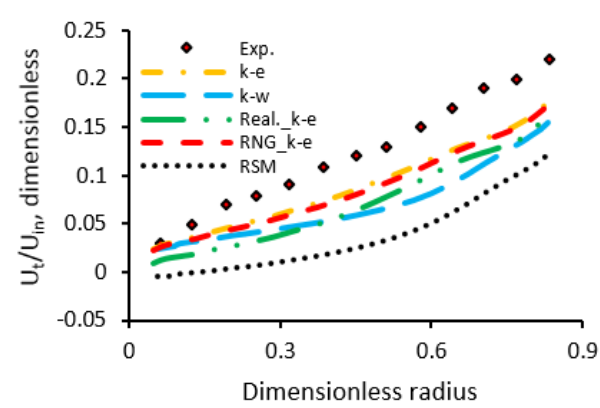

(a) Observation angle $0^{0}$

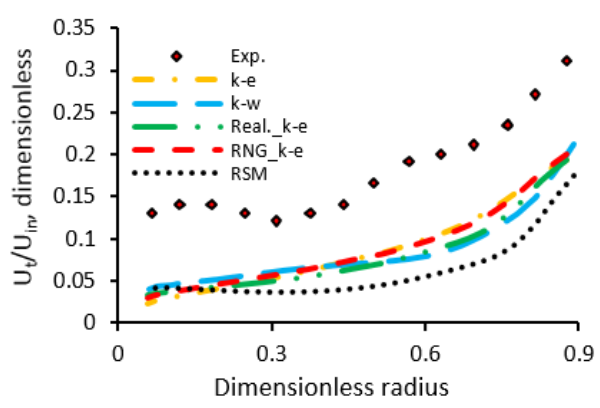

(b) Observation angle $90^{\circ}$

Figure 6. Tangential velocity profiles in the DTC 
The simulation results obtained by Gupta and Kumar [5] using RNG k- $\varepsilon$ turbulence model are deviated $55 \%$ for angle position $90^{\circ}$ and $16 \%$ for angle position $0^{\circ}$. The deviations of our simulations are $54 \%$ for angle position $90^{\circ}$ and $32 \%$ for angle position $0^{0}$. Although, the discrepancies between the predicted and the measured data are considered to be significant, but qualitatively, all turbulence models could predict the trends of the tangential velocity profiles in the TJC, fairly well. It is expected that RSM turbulence model performance is better in this case, but it is not so. Even here, the standard k- $\varepsilon$ and RNG k- $\varepsilon$ turbulence models are slightly superior to the RSM turbulence model. The results obtained are consistent with the findings of Escue and Cui [11] for a low tangential flow in which the prediction results of k- $\varepsilon$ models are relatively better than the prediction results of the RSM model.

\section{Tangential Jet Chamber}

The performances of the turbulence models are further evaluated for the flow case in the TJC. Here, the predictions of various turbulence models are compared to the measured velocity profiles from Chen et al. [8]. The comparisons are shown in Figure 7. The simulation results with RSM turbulence model in the CFX-4 CFD code reported by Chen et al. [8] deviated $31 \%$ for tangential velocity and $14 \%$ for the axial velocity from the experimental data. While our simulations, using RSM in the Ansys Fluent CFD code, deviate $39 \%$ for tangential velocity and 4\% for axial velocity, as shown in Figure 7.

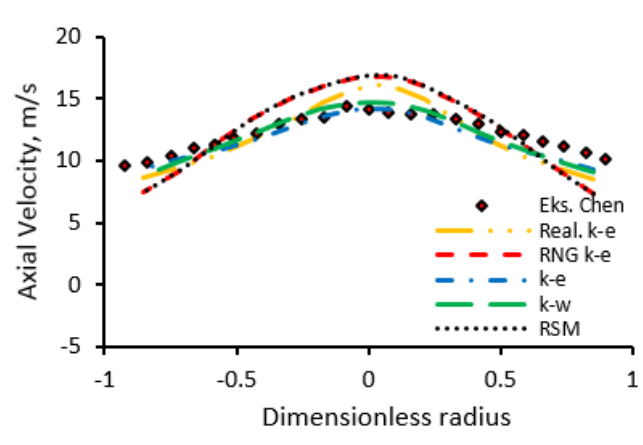

(a) Axial velocity

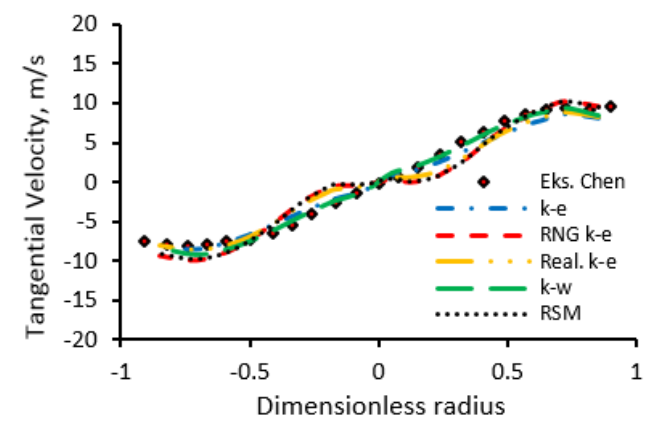

(b) Tangential velocity

Figure 7. Axial and tangential velocity profiles in a TJC (at $\mathrm{z}=0.6278 \mathrm{~m}$ and $\mathrm{I}_{\mathrm{IT}}=0.8$ )

All turbulence models work accurately to predict the trends and the values of the experimental data. The performance of standard $k-\varepsilon$ and $k-\omega$ models are slightly superior to the other models, especially in predicting the flow profiles at the center of the chamber. This is consistent with the statement of Nemoda et al. [9], where for low swirl numbers $\left(\mathrm{S}_{\mathrm{N}}=0.87-1.7\right)$, the velocity profiles in a TJC are properly predicted by the k- $\varepsilon$ models (standard and RNG). However, for high swirl flows $\left(\mathrm{S}_{\mathrm{N}}>2.8\right)$, the prediction results from $\mathrm{k}-\varepsilon$ models begin to deviate from experimental data. In this case, the RSM turbulence model works better. In line with this statement, Bourgouin et al. [13] proposed that for very high tangential flow, the flow simulation in a TJC should require a more sophisticated turbulence model, such as LES turbulence model. The successfuls of the ke model use, in predicting the flow structure in TJC, were also reported by Noor et al. [33] and Treedet \& Suntivarakorn [34].

The performance evaluations of the turbulence models to the three types of cyclonic flows above revealed that each turbulence model has its own limitations. There is no 
single turbulence model to be the most accurate for all geometries and flow conditions. Although, the RSM turbulence model is expected, theoritically, to be better in predicting the tangential flow than eddy viscosity models ( $k-\varepsilon$ and $k-\omega$ models), but the reality is not so. For the flow in the DTC, the predictions by the RSM model at a low inlet velocity $\left(u_{\text {in }}\right.$ $=1.057 \mathrm{~m} / \mathrm{s}$ ) are less accurate than the predictions by the eddy viscosity models. The performances of RSM model, at low tangential flow, are also less accurate compared to the results of the eddy viscosity models for the case of the TJC flow. The statement, that the RSM model is not always superior in all cases of fluid flow, has also been delivered by Vazquez [12].

Someone may post a question about the difference between the flow pattern that is predicted by the RSM and the standard $k-\varepsilon$ model. To answer the equation, the flow pattern described by the flow structure in the GTC is presented. This flow structure is constructed from the flow pathline starting from an inlet position $(x, y, z)$. A mass less particle is released from the starting position and tracked to the downstream with the pathline principle by applying $\bar{u}_{x}=\partial x / \partial t, \bar{u}_{y}=\partial y / \partial t$ and $\bar{u}_{z}=\partial z / \partial t$. The predicted flow structures in a GTC using the RSM and standard k- $\varepsilon$ turbulent are compared in Figure 8. Referring to Figure 8, the answer for the question above is that the difference is not so significant for the design optimization purpose.

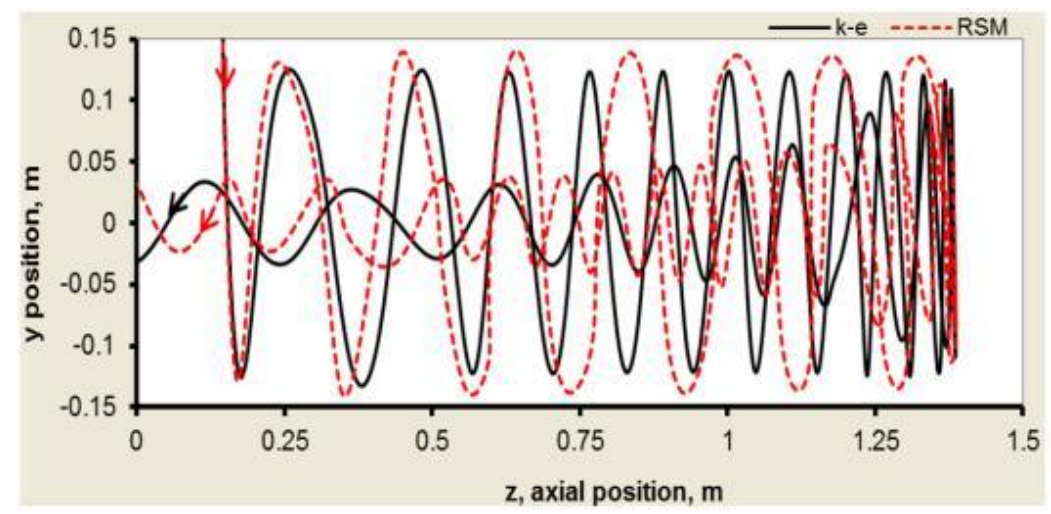

Figure 8. Comparison between the predicted vortex structure using RSM and standard k- $\varepsilon$ turbulence models in the GTC

The optimization of the design using the CFD technique is required. Working with many geometry and operating variables, the computational effort of RSM turbulent will be very massive. By considering the things above, it could be concluded that for the engineering design purposes, the eddy viscosity turbulence models is more realistic and consistently robust for different types of flow. The standard or RNG k- $\varepsilon$ model is proved to be the robust and easy to arrive on the converged solution for all types of flows. Therefore, the next numerical CFD investigation, which is intended for the process unit design, is more convincing to use the standard or RNG k- $\varepsilon$ turbulence model.

\section{Three Dimensional Structures of Cyclonic Turbulent Flows}

In this sub section, numerical investigations are conducted to explore in depth the flow structure in all three chambers mentioned above. Parameters in the simulation process are given in Table 6. Meanwhile, the boundary conditions for all three cases are given in the Table 7. 
Table 6. Parameters in the simulation process

\begin{tabular}{ll}
\hline Parameter & Value \\
\hline $\begin{array}{l}\text { Turbulence model } \\
\text { Pressure-velocity coupling } \\
\text { scheme }\end{array}$ & Standard k- $\varepsilon$ \\
Spatial discretization scheme & SIMPLE \\
& $-\mathrm{p}=$ Second order, except for the GTC \\
& $-\mathrm{u}_{\mathrm{i}}=$ case were Presto scheme was used \\
& $-\mathrm{k}=$ First order upwind \\
& $-\varepsilon=$ First order upwind \\
Solver & Steady state and pressure-based with absolute \\
& velocity formulation \\
Gravity & No effect \\
Mesh type & Hexagonal elements \\
Mesh size & $2.5 \%-7.5 \%$ of the chamber diameter \\
Operating pressure & 101325 Pa \\
Flow media & - Air for GTC \\
& - Water for DTC \\
& - Air for TJC \\
Geometry and dimension & Given in Figure 1 \\
\hline
\end{tabular}

Table 7. Boundary conditions for all three cases (GTC, DTC and TJC)

\begin{tabular}{|c|c|c|}
\hline $\begin{array}{l}\text { Boundary } \\
\text { Conditions }\end{array}$ & Variable & Magnitude \\
\hline \multirow[t]{6}{*}{ Inlet } & Magnitude velocity, $\mathrm{u}_{\text {in }}$ & Fixed \\
\hline & Turbulent Intensity, I & $\mathrm{I}=5 \%$ \\
\hline & Hydraulic Diameter, $\mathrm{D}_{\mathrm{H}}$ & $\begin{array}{l}\text { Calculated from the inlet cross } \\
\text { section area }\end{array}$ \\
\hline & Turbulent length scale, $\ell$ & $\ell=0.07 \mathrm{D}_{\mathrm{H}}$ \\
\hline & Turbulent kinetic energy, $\mathrm{k}$ & $\mathrm{k}=3 / 2\left(\mathrm{u}_{\mathrm{in}} \mathrm{I}\right)^{2}$ \\
\hline & Kinetic energy dissipation rate, $\varepsilon$ & $\varepsilon=C_{\mu}^{3 / 4} \frac{\mathrm{k}^{3 / 2}}{\rho}$ \\
\hline \multirow[t]{4}{*}{ Wall } & Velocities & Zero \\
\hline & Pressuure, $\mathrm{p}$ & Zero \\
\hline & Turbulent kinetic energy, k & Zero \\
\hline & Kinetic energy dissipation rate, $\varepsilon$ & Zero \\
\hline Outlet & Velocities & Zero gradient \\
\hline
\end{tabular}

\section{Flow Structures in the GTC}

The simulation results revealed that there are two major flow structures in the GTC. One is the flow structure which is formed by the direct short cut of the flow path lines from the inlet to the vortex finder and to the chamber outlet, Figure 9a. This type of flow structure would cause the solid particles to be directly exhausted from the gas outlet.

The second type of the flow structures is the vortex flow structure, Figure $9 \mathrm{~b}$. This vortex structure is formed by two spiral flow structures namely the outer spiral flow and the inner spiral flow. The outer spiral flow is started from a release point at the inlet and go to the bottom of the chamber. The number of the outer spirals in the GTC is known as 
the number of turns $\left(\mathrm{N}_{\mathrm{e}}\right)$ in the cyclone design [35]. The outer spiral flow ends at the bottom of the chamber and is converted into an inner spiral flow in the reverse direction with the outer spiral flow. This vortex structure is responsible to the settling process of the solid particles. The DTC is commonly used for the solid particle separation.

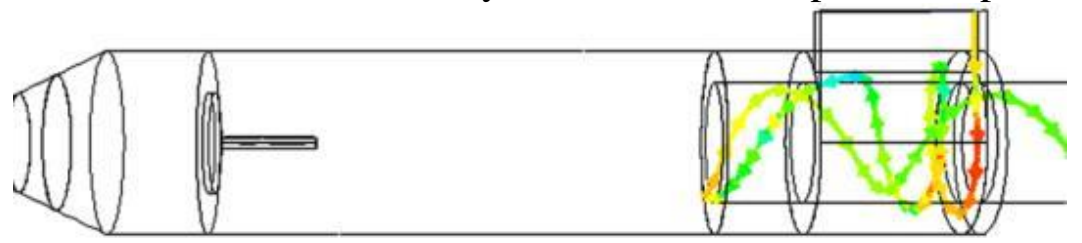

(a) Short cut flow pattern

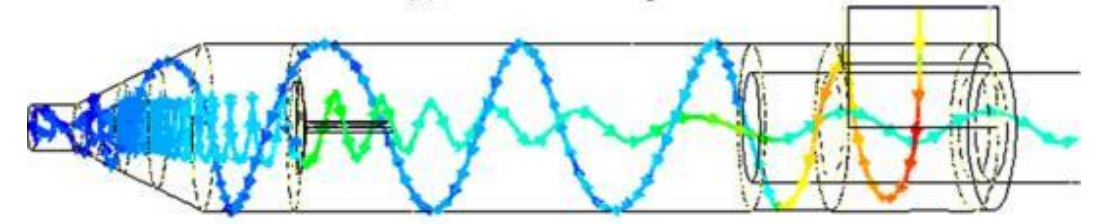

(b) Recirculation flow pattern

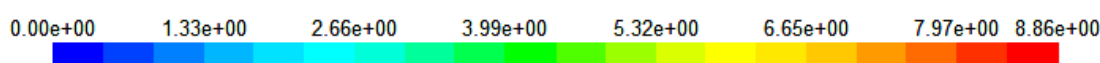

Figure 9. The generated flow structures by the flow path line from a single released point at the inlet of GTC (colored by the magnitude velocity in $\mathrm{m} / \mathrm{s}$ )

\section{Effect of the vortex stabilizer diameter}

The vortex stabilizer is used to improve the separation efficiency in the GTC by splitting the vortex core into two parts. The comparison of the generated vortex core from the GTC without a vortex stabilizer and the GTC with a vortex stabilizer is shown in Figure 10. The GTC without a vortex stabilizer has only one clear vortex core that extends from the cone base towards the gas outlet, Figure 10a. While the GTC with a vortex stabilizer has two vortex cores. Those are a primary vortex core that extends from the vortex stabilizer towards the gas outlet and a secondary vortex core that located between the vortex stabilizer to the dust hopper, Figure 10b. The vortex stabilizer establish physically the vortex core size to follow the vortex stabilizer diameter $\left(D_{\mathrm{vs}}\right)$.

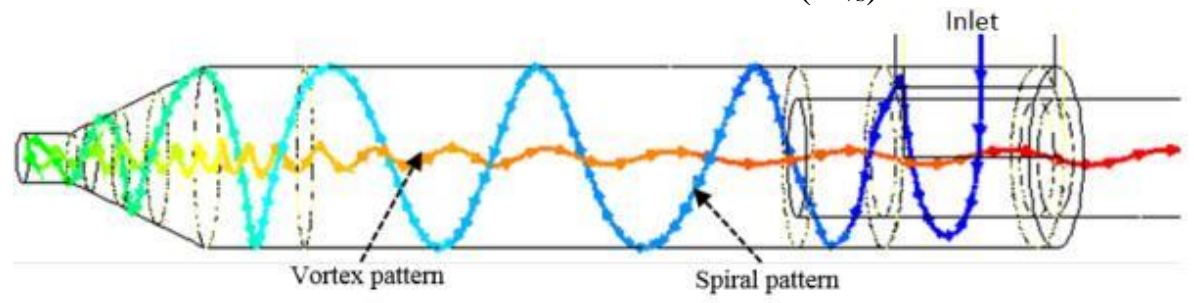

(a) Vortex structure inside the GTC without vortex stabilizer (3.2 s after injection)

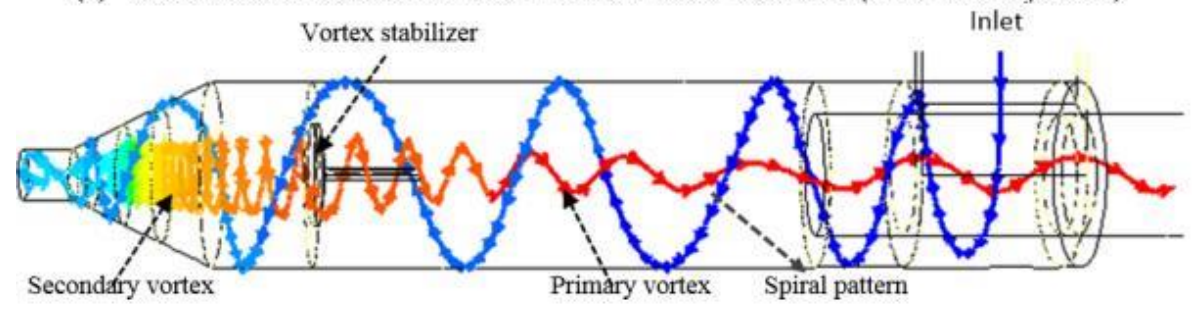

(b) Vortex structure inside the GTC with vortex stabilizer ( $9.3 \mathrm{~s}$ after injection)

Figure 10. The vortex structure in the GTC without and with a vortex stabilizer after a certain injection time. 
In the range of $D_{v s}$ values varied (0.52 - 0.86 of the chamber diameter), it was found that the greater the $D_{v s}$, the greater the vortex core size, Figure 11 . The $D_{v s}$ also influence the tangential velocity and pressure drop in GTC; the greater the $\mathrm{D}_{\mathrm{vs}}$, the greater the maximum tangential velocity and the pressure drop $(\Delta \mathrm{p})$ would be. The maximum tangential velocity profile is identified along the separation zone (barrel) of the chamber for each vortex finder diameter $\left(\mathrm{D}_{\mathrm{vf}}\right)$. At $\mathrm{z}=0.75 \mathrm{~m}$, the values of the maximum tangential velocity are $5.65 \mathrm{~m} / \mathrm{s}$ in the GTC without a vortex stabilizer and $5.76 \mathrm{~m} / \mathrm{s}$ in the GTC with a vortex stabilizer. The effect of $D_{v s}$ on the $\Delta p$ is very clear. The pressure drops are obtained $28 \mathrm{~Pa}$ in the GTC without a vortex stabilizer, $42 \mathrm{~Pa}$ in the GTC with $\mathrm{D}_{\mathrm{vs}}=0.55$ $\mathrm{D}_{\mathrm{c}}, 48 \mathrm{~Pa}$ in the GTC with $\mathrm{D}_{\mathrm{vs}}=0.66 \mathrm{D}_{\mathrm{c}}$, and $52 \mathrm{~Pa}$ in the GTC with $\mathrm{D}_{\mathrm{vs}}=0.72 \mathrm{D}_{\mathrm{c}}$. Here, the pressure drop is defined as the pressure difference between the center of cone base and the center of gas outlet.

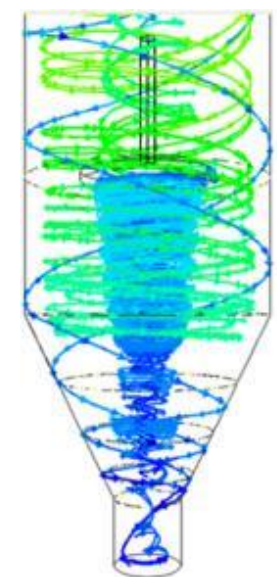

(a) Dvs $=0.16 \mathrm{~m}$

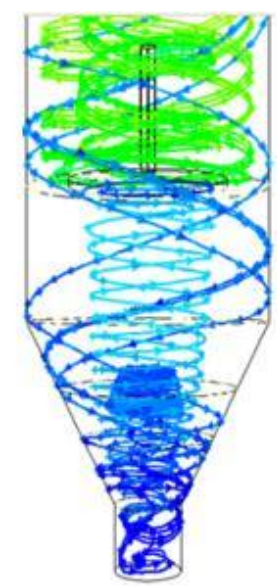

(b) $\mathrm{D}_{\mathrm{vs}}=0.19 \mathrm{~m}$

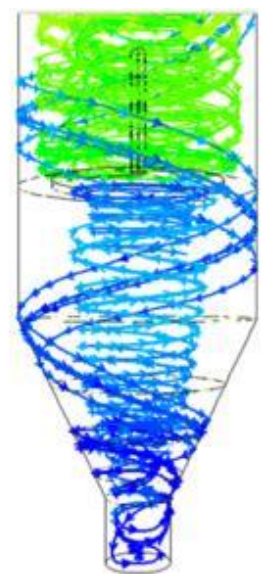

(c) Dvs $=0.21 \mathrm{~m}$

$\begin{array}{lllllllll}0.00 \mathrm{e}+00 & 1.33 \mathrm{e}+00 & 2.66 \mathrm{e}+00 & 3.99 \mathrm{e}+00 & 5.32 \mathrm{e}+00 & 6.65 \mathrm{e}+00 & 7.97 \mathrm{e}+00 \quad 8.86 \mathrm{e}+00\end{array}$

Figure 11. The comparison of the vortex core size in the GTC at various vortex stabilizer diameters $\left(\mathrm{D}_{\mathrm{VS}}\right)$ (colored by the velocity magnitude).

\section{Effect of the inlet aspect ratio}

The variations in the inlet aspect ratio here were made by keeping the tangential inlet width and varying the tangential inlet height. The effect of the inlet aspect ratio is evaluated to the maximum tangential velocity and to the pressure drop. The greater the $\mathrm{R}_{\mathrm{IA}}$ value that is employed, the greater the maximum tangential velocity and the pressure drop are produced. At the axial position $\mathrm{z}=0.75 \mathrm{~m}$ and the $\mathrm{R}_{\mathrm{IA}}$ values of $4.5,5.7$, and 8.6 , the maximum tangential velocities are $5.7 \mathrm{~m} / \mathrm{s}, 7.1 \mathrm{~m} / \mathrm{s}$ and $8.1 \mathrm{~m} / \mathrm{s}$, respectively. While the pressure drops for these conditions are $42.2 \mathrm{~Pa}, 53.1 \mathrm{~Pa}$, and $56.6 \mathrm{~Pa}$, successively.

The $\mathrm{R}_{\mathrm{IA}}$ slightly influences the vortex core frequency $\left(\mathrm{F}_{\mathrm{VC}}\right)$. The vortex core structure is generated from the pathline position in the axial (z) position and the radial position. The resulted vortex structures are shown in Figure 32. At the $\mathrm{R}_{\mathrm{IA}}$ value of 4.5, the number of the vortex core frequency along the barrel zone ( $\mathrm{z}=0$ to $1.2 \mathrm{~m})$ is 8 . While at the $\mathrm{R}_{\mathrm{IA}}$ value of 8.6 , the number of vortex core frequency along the barrel zone is 9 . 


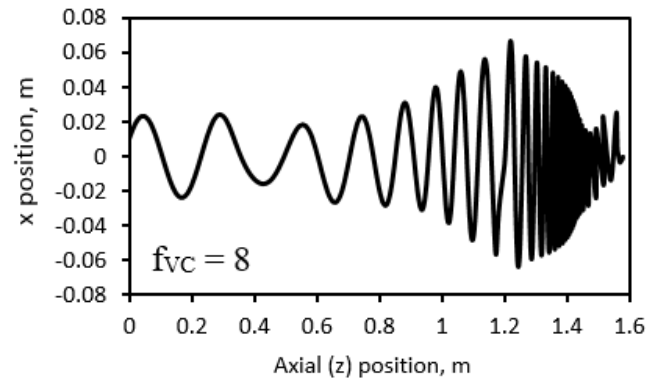

Inlet aspect ratio $\left(\mathrm{R}_{\mathrm{IA}}\right)=4.5$

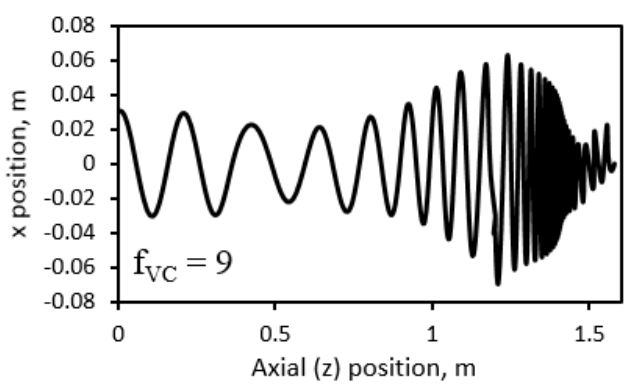

Inlet aspect ratio $\left(\mathrm{R}_{\mathrm{IA}}\right)=8.6$

Figure 32. The effect of inlet aspect ratio to the vortex core frequency

\section{Flow Structures in the DTC}

The simulation results show that the flow structure in the DTC is very much complex. This structure is formed by various patterns of the flow. One is classified as a non-vortex structure. This structure is characterized by the non-recirculated flow from the inlet to the outlet. They might undergo the spiral type flow, but they keep their directions toward the outlet. One spiral wave is defined as a spiral that starts from a bottom starting point to the next bottom ending point. These CFD results revealed that the non-vortex structure has several spiral patterns. These patterns are shown in Figure 13. The spiral pattern might have 1.5 waves (Figure 13a), 2.5 waves (Figure 13b), 4.5 waves (Figure 13c), 3 waves (Figure 13d) and more.

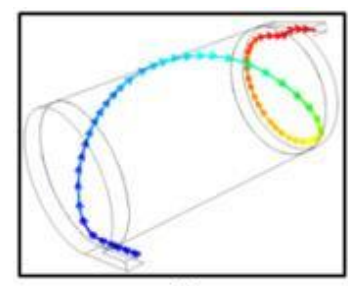

(a)

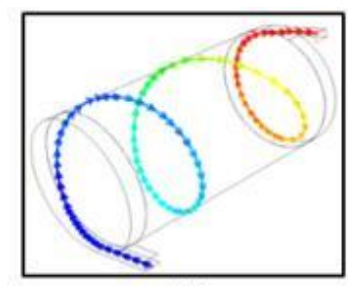

(b)

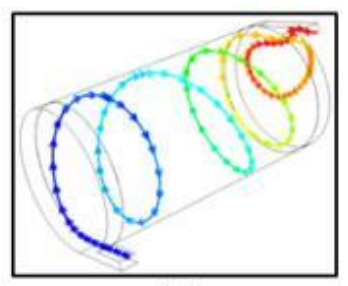

(c)

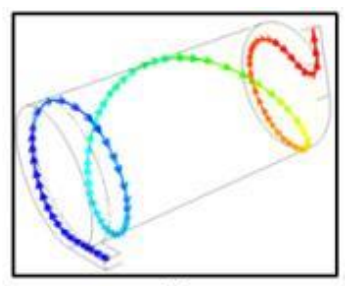

(d)

Figure 13. Non vortex flow structures in the DTC for different released points

The second type of the flow structure inside the DTC is identified as multilayer vortex structures. It could be two, three and many layers, as shown in Figure 14. The two adjacent layers at the center have the opposite direction to each other. The first shape of such this vortex structure is constructed by three layer spiral flows that are closer to the wall,

Figure 144a. The second shape of the three layer spiral flow is shown by Figure $14 \mathrm{~b}$, for $\mathrm{I}_{02}$ inlet-outlet orientation. This shape is characterized by a concentrated spiral flow like a reversed tornado tail from the downstream to upstream. The other two layers locate near to the chamber wall.

The vortex structures that have more than three layers are observed for the $\mathrm{I}_{01}$ and $\mathrm{I}_{05}$ inlet-outlet orientations. These are shown by Figure $14 \mathrm{c}$ and by Figure $14 \mathrm{~d}$. The multilayer vortex structure, Figure 14d, has a concentrated vortex core at the center region with the flow direction from downstream to the upstream. The layers of the vortex structure in Figure 14c are closer to the wall surface. Each layer forms a spiral flow type. 


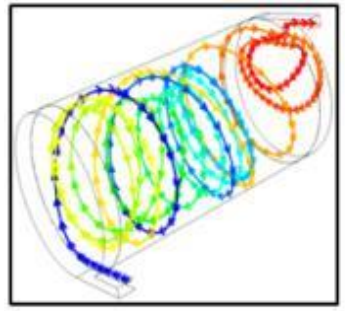

(a)

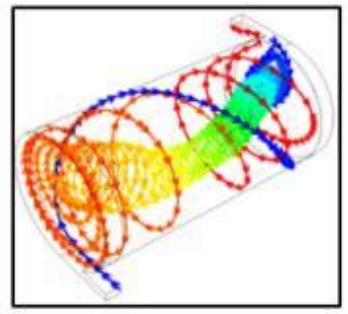

(b)

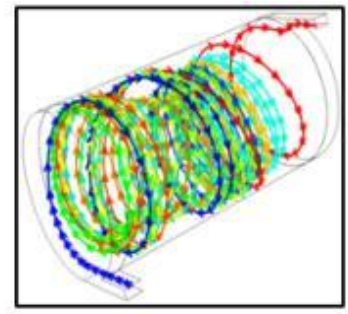

(c)

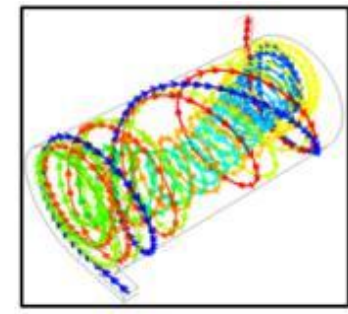

(d)

Figure 14. Multilayer vortex structures of the flow in the DTC that are generated from different released points at different inlet-outlet orientations

The position of a multilayer vortex core is tracked with the time after $8 \mathrm{~s}, 20 \mathrm{~s}, 40$ s, $47 \mathrm{~s}$, and $91 \mathrm{~s}$ from the released point at the inlet face. These positions are shown in Figure 15.
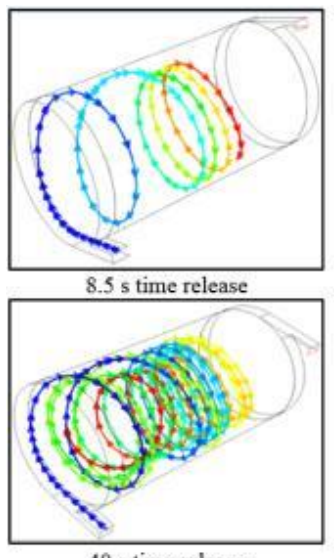

40 s time release

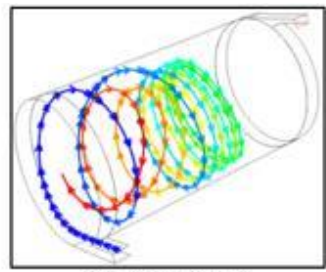

$20 \mathrm{~s}$ time release

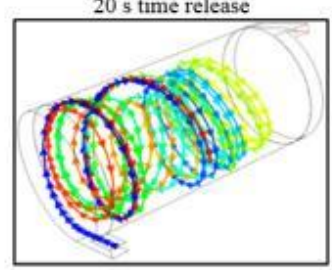

$47 \mathrm{~s}$ time release
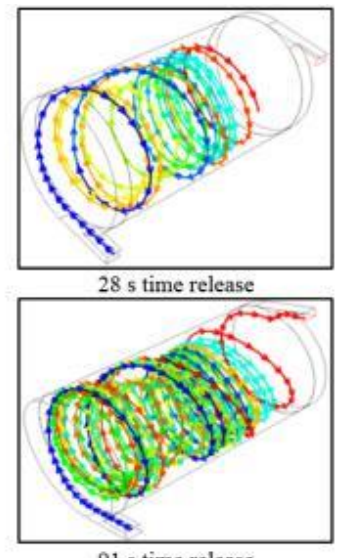

$91 \mathrm{~s}$ time release

Figure 15. The tracking position of a multilayer vortex structure inside the DTC cavity from a released point at the inlet face.

The third type of the flow structure is the unending flow structure, as depicted in Figure 16. The end point of the flow structure never reach the outlet surface. The end point keeps moving inside the cavity. There are four patterns of this unending flow structure. The first is the multilayer unending vortex structure with an inner core spiral flow from the downstream to the upstream,

Figure 166a. There are many outer spiral flow layers. Finally, the flow keeps moving circularly around the wall. The second pattern is shown by Figure 16b. Only multi layers of the outer spiral flow characterize the flow path line. The end point of the path line also keep moving similarly to the pattern in

Figure 165a. The third pattern is an unending non vortex spiral flow in which the end point keeps moving toward a point at the wall, Figure 16c. The fourth pattern of the unending flow structure is a multiple layer tornado like vortex structure. This is shown by Figure 16d. 

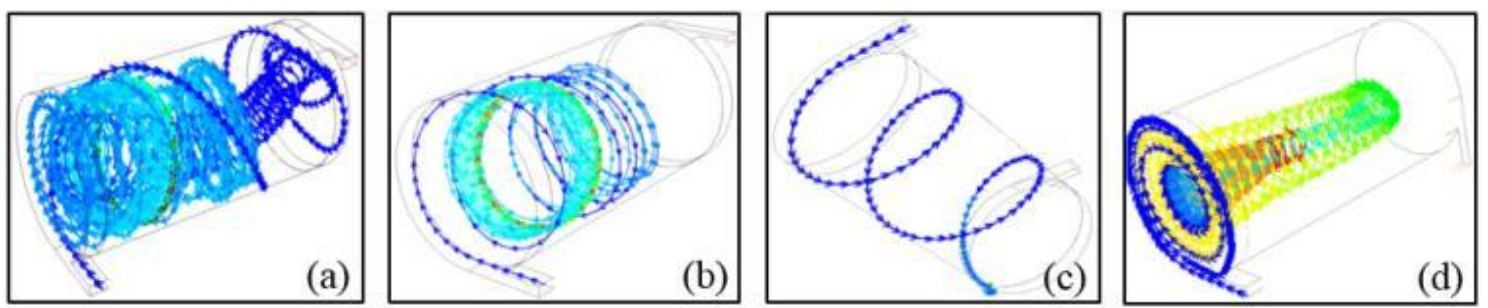

Figure 16. The unending flow structures in the DTC that are generated from different released points at different inlet-outlet orientations

The histories of the flow structures are then tracked inside the DTC cavity from time to time. First, the outer tangential flow is initiated near the tangential inlet region, Figure 17a. This tangential flow continues to shrinkage radially toward the center of the cavity Figure 17b. A first like tornado tail path line near the cavity centerline as the first inner vortex core is generated from the upstream to the downstream, Figure 17c. It is continued by the first outer spiral flow with the direction from the downstream to the upstream as the first outer vortex core, Figure 17d. The first outer core path line is continued to the second inner core path line, Figure 17e. The second outer core path line is generated as the continuation of the second inner core path line, Figure 17f. Such these cycles continue to generate the third, fourth and more layers. It is an interesting phenomenon about the next outer spiral flow path line that occurs, Figure 17g and Figure 17h. Finally, the endpoint of the path line never stops and flows circularly around the cavity wall, Figure 17i.

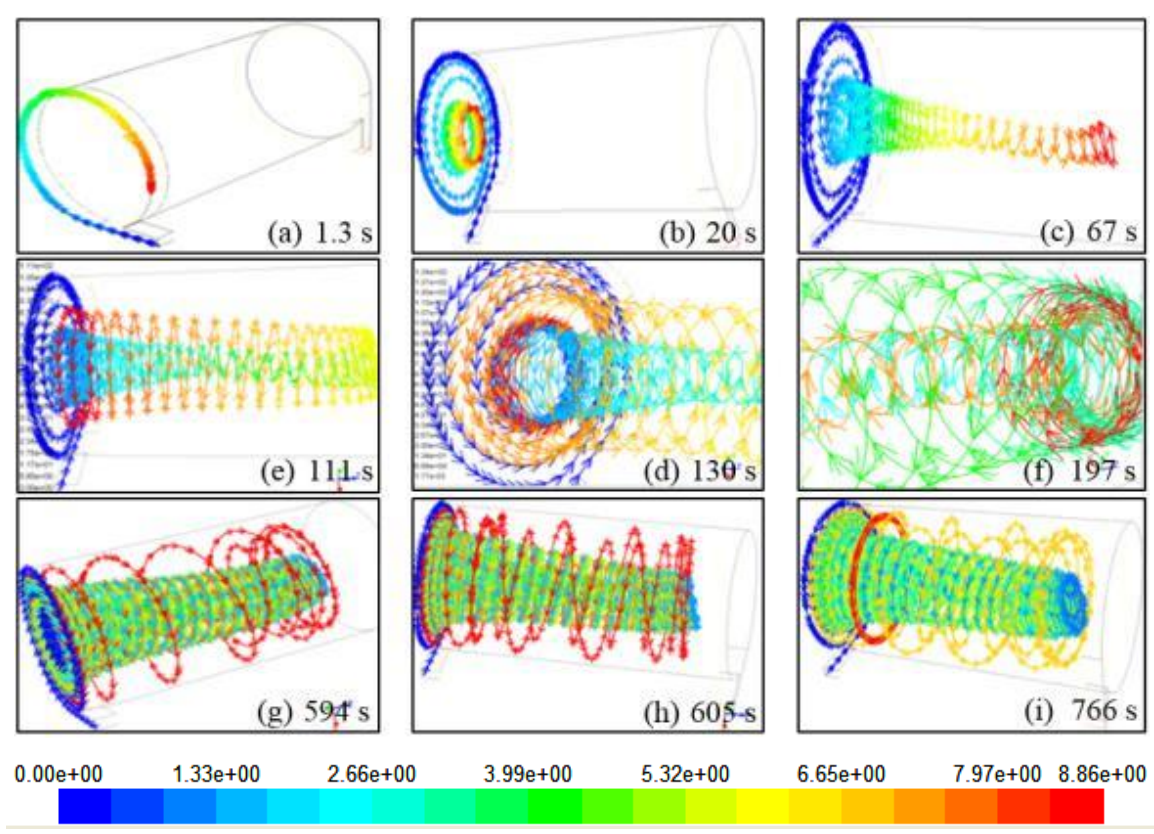

Figure 17. The tracks of an unending flow structure as a multiple layer tornado like vortex pattern in the $\mathrm{I}_{06}$ inlet-outlet position that is generated from a released point

The influences of the outlet position to the flow structure are also investigated here. There are twelve variations of the outlet position being studied, Figure 2. From this investigation, the results show that the outlet position influences the vortex structure path 
line and the fluid traveling time. Both non-vortex and multilayer vortex core structures exist for all inlet-outlet orientations. The shapes of the multilayer vortex structure for all of the inlet-outlet orientations and the traveling time are composed by the flow structure components in Figure 139, Figure 20 and Figure 21. The typical precessing vortex core (PVC) for each inlet-outlet orientation in the DTC are compared in Figure 18.
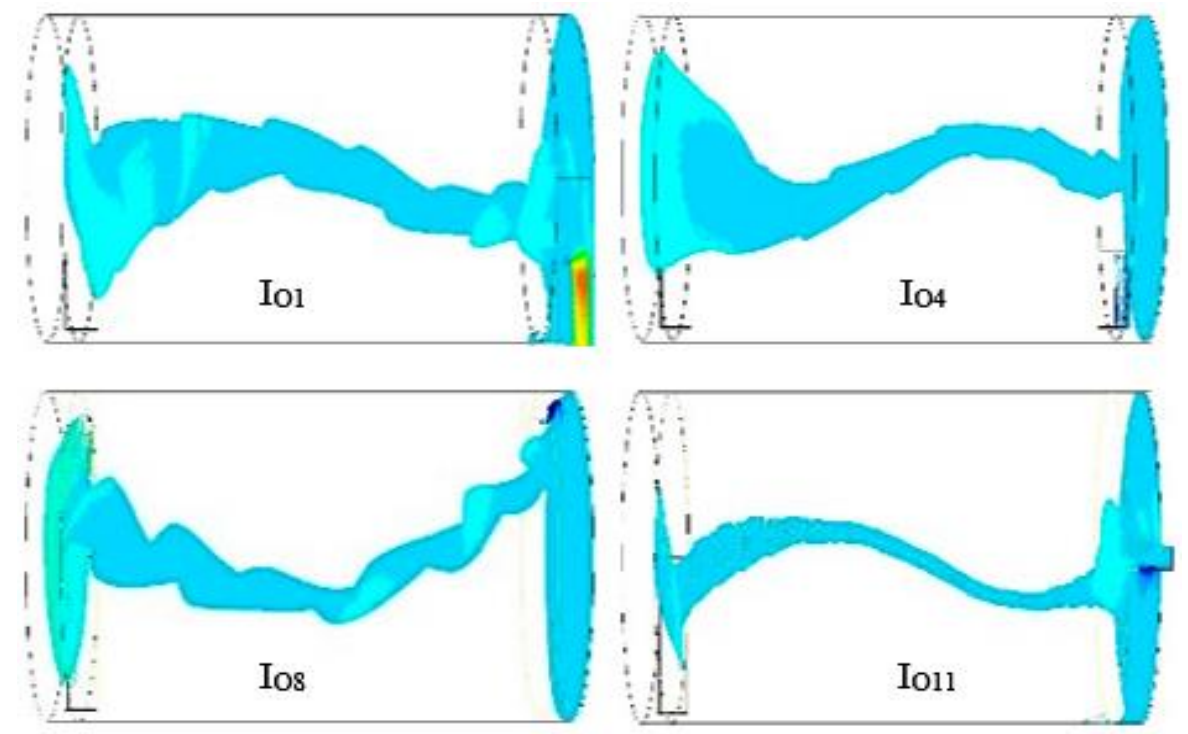

Figure 18. Individual precessing vortex core for 4 inlet-outlet orientations

The velocity profiles inside the DTC are compared to evaluate the effects of the inlet-outlet orientations. The axial and tangential velocity profiles are plotted at the centerline of the DTC cavity, the axial line at the distance closer to the DTC wall, and a radial line at the half axial distance of the cavity. The effects of the inlet-outlet orientations are clearly shown on the axial and tangential velocity profiles at the cavity centerline, Figure 49. The axial velocity profiles at the centerline for all of the inlet-outlet orientations are shown in Figure 49a. The negative values of the axial velocity indicate that the flows are returned to the upstream and it means that the vortex pattern is formed.

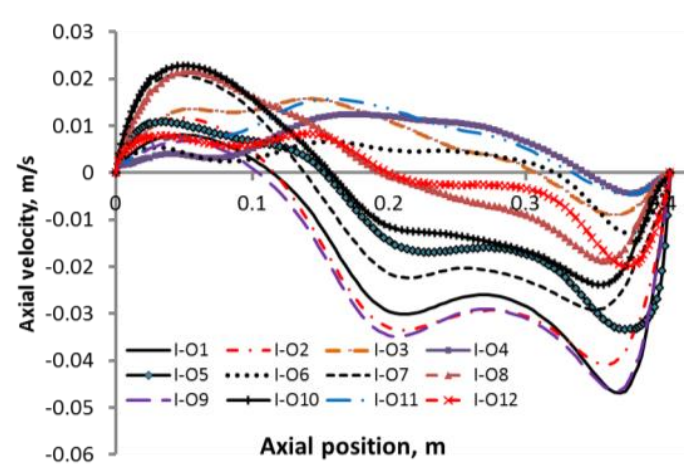

a)

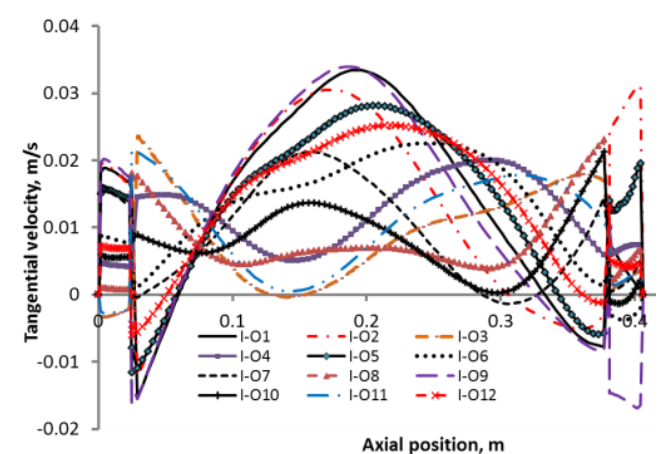

b)

Figure 49. The velocity profiles at the centerline of the DTC cavity for various inlet-outlet orientations.

The strong tangential velocity occurs at the region near to the wall. The tangential velocity profiles along the axial line at the distance 0.9 radius are affected slightly by the 
inlet-outlet orientations, Figure 20a. The profiles are different from the axial velocity profiles in which each inlet-outlet orientation exhibits a different axial velocit profile at this line, Figure 20b.

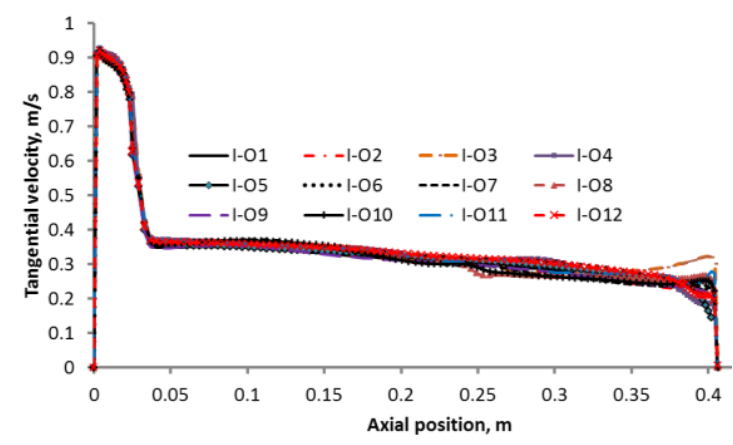

a)

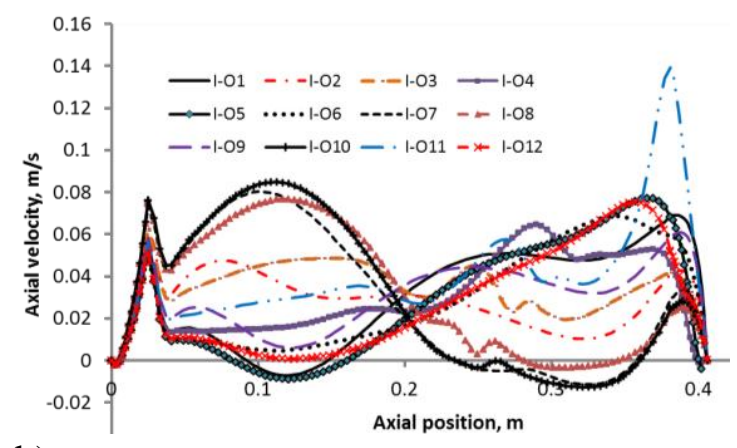

b)

Figure 20. The velocity profiles along the axial line at the distance $0.9 \mathrm{R}$ in the DTC cavity for various inlet-outlet orientations.

The peaks of both tangential and axial velocity profiles occur near the wall region. They are shown by the tangential and axial velocity profile at the radial line from the wall to another opposite wall at the half axial distance of the DTC cavity. The effect of the inlet-outlet orientation on the velocity profiles is clearly presented by Figure 21.

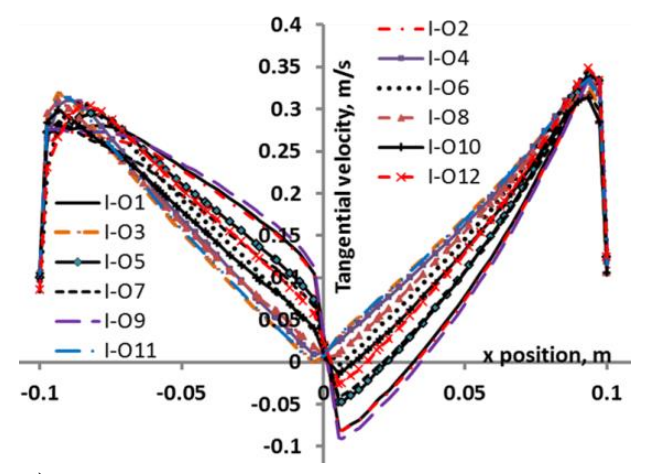

a)

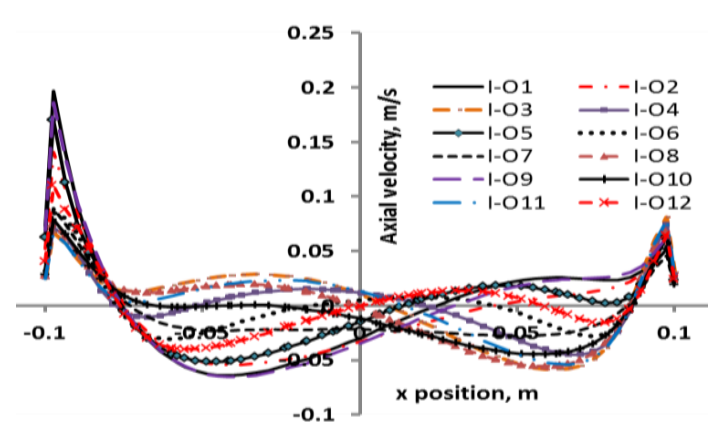

b)

Figure 21 . The velocity profiles along a radial line from the wall to another opposite wall at a half axial distance in the DTC cavity

\section{Flow Structures in the TJC}

The investigated TJC here is one of the unconfined swirl burner type. The simulation results in the TJC reveals that the flow structures are constituted by the helical pattern at the peripheral section and wavy axial pattern at the center region, as shown in Figure 22. Although this case involves swirl flow, but there is no recirculation flow was found. This is related to the outlet boundary condition of the burner used, which includes the unconfined type. According to Vazquez [12], the recirculation flow is only found in the confined swirl burners.

Unlike the GTC and DTC which are the separation chambers, the TJC is considered as a mixing or a combustion chamber. Therefore, the flow structure in the TJC affects the degree of mixing, flame stability, combustion eficiency and heat transfer rate $[9,36]$. 


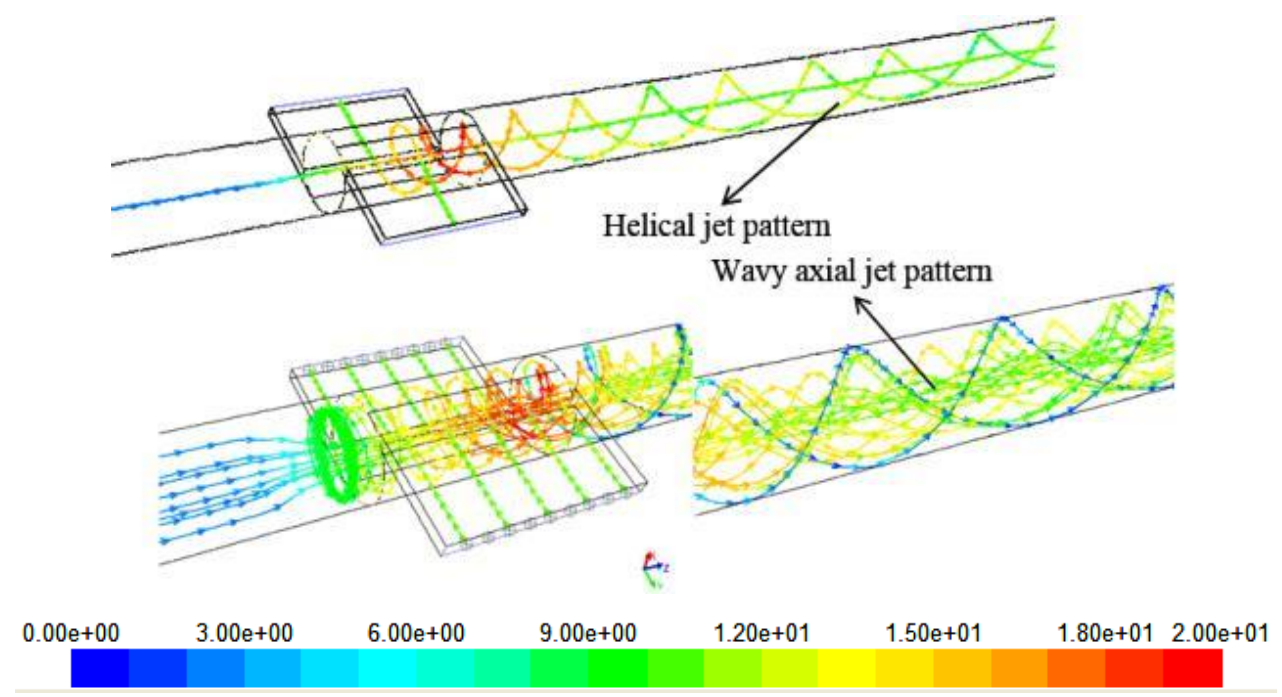

Figure 22. Helical jet and wavy axial jet flow structures in the TJC

\section{Effect of the inlet aspect ratio ( $\left.\mathrm{R}_{\mathrm{IA}}\right)$ on the velocity profiles}

The axial and tangential velocity profiles of the TJC flow at $\mathrm{I}_{\mathrm{IT}}$ value 0.8 and inlet aspect ratios at 15, 28.6 and 40 are shown in Figure 23. The axial velocity profile indicates that there is no any back flow phenomenon in the TJC. All axial velocities have positive values at all $\mathrm{R}_{\mathrm{IA}}$ values, Figure 23a. This is a reason that the vortex pattern in the TJC is not generated. While the curve in Figure $23 \mathrm{~b}$ shows that the tangential velocity is affected by the inlet aspect ratio $\left(\mathrm{R}_{\mathrm{IA}}\right)$. The higher the $\mathrm{R}_{\mathrm{IA}}$ value, the lower the tangential velocity value is.

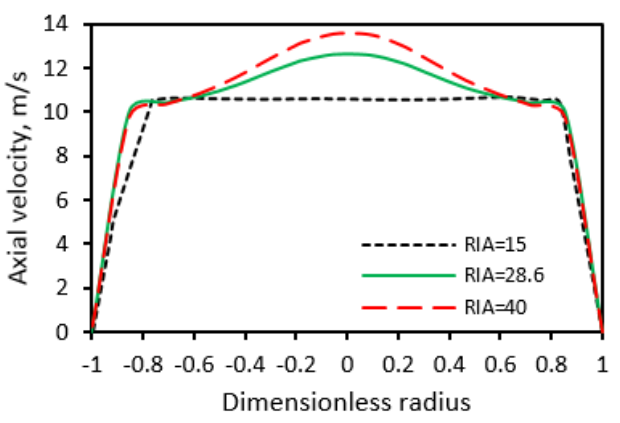

(a) Axial velocity

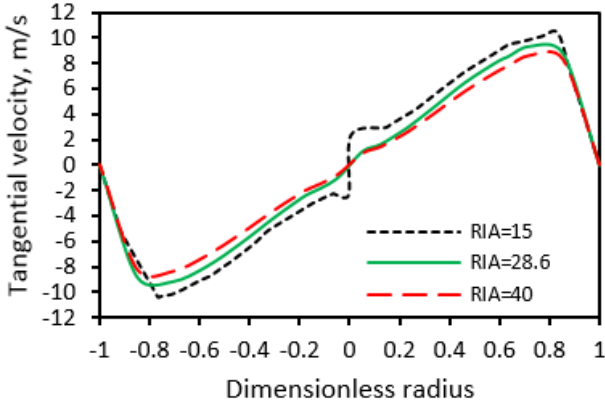

(b) Tangential velocity

Figure 23. Axial and tangential velocity profiles in the TJC at several $\mathrm{R}_{\mathrm{IA}}$ values

\section{Effect of IIT value on the Helical Number of Jet $\left(\mathrm{NJH}_{\mathrm{JH}}\right)$}

The initial tangential intensity influences the asymmetrical shape of the flow [8]. In this study, at $\mathrm{R}_{\mathrm{IA}}$ value of 28.6 , the asymmetric flow is found at the $\mathrm{I}_{\mathrm{IT}}$ value of 0.75 . This is shown by Figure 24.

The initial tangential intensity also greatly affects the flow pattern and mixing characteristic of the flow. The helical number of jet $\left(\mathrm{N}_{\mathrm{JH}}\right)$ in the TJC is influenced by the IIT. The higher the IIT value, the higher the helical number of jet is. The helical jet number is 20 for the $\mathrm{I}_{\text {IT }}$ value of $1.7,10$ for the $\mathrm{I}_{\text {IT }}$ value of $0.75,3$ for the $\mathrm{I}_{\text {IT }}$ value of 0.26 , and 1 for the $\mathrm{I}_{\mathrm{IT}}$ value of 0.03 . The helical flow structures for various $\mathrm{I}_{\mathrm{IT}}$ values are shown in Figure 25. 


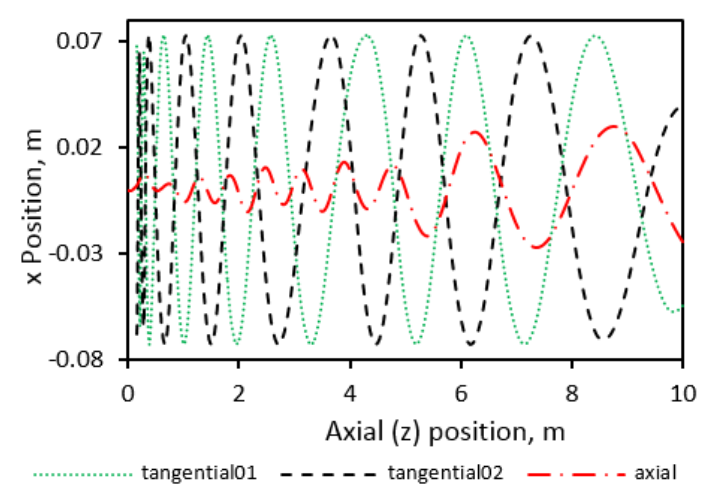

Figure 24. The asymmetric flow pathlines inside the TJC

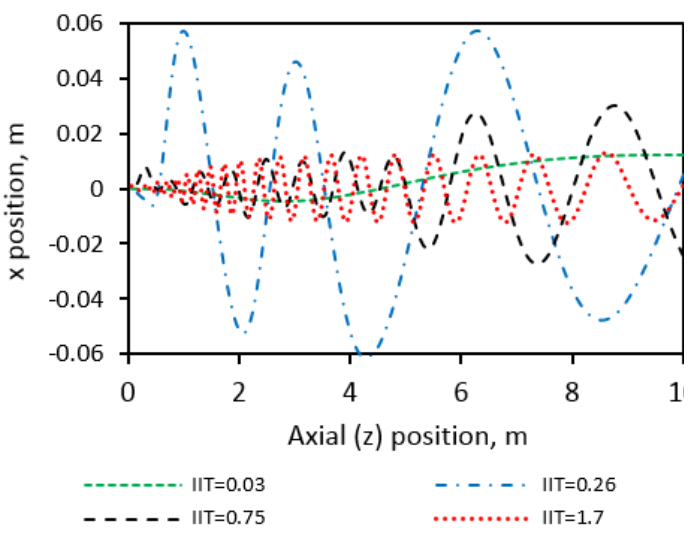

Figure 25. The helical jet flow pathlines at several $\mathrm{I}_{\mathrm{IT}}$ values

The helical jet size is measured by the amplitude of the helical wave as shown in Figure 25 above. This size is inversely proportional to the $\mathrm{I}_{\mathrm{IT}}$ value.The higher the $\mathrm{I}_{\mathrm{IT}}$ value, the smaller the helical jet size is.

\section{CONCLUSION}

The selection for the turbulence model has been determined by its acceptable simulation performances and its low computational effort. Every turbulence model has its own drawback. No single turbulence model is consistently superior to the others. The standard $k-\varepsilon$ model is a robust turbulence model and has relatively smaller computational effort. Any $k-\varepsilon$ turbulence model is more realistic choice for the engineering design purposes. The standard $k$ - $\varepsilon$ model shows that the flow structures in the GTC and the DTC are formed by the vortex structure. The flow structure in the GTC is formed by a spiral pattern near the wall region and a vortex pattern in the center. The formation of the vortex pattern is caused by the back flow phenomena. In the GTC, the vortex stabilizer diameter influences the vortex pattern. The larger the diameter of vortex stabilizer, the greater the vortex core size is formed. The vortex core size affects the velocity profile axially and tangentially. The greater the size of vortex, the smaller axial velocity and the greater the tangential velocity is produced. The inlet-outlet orientation of the DTC generates specific flow structures. There are three groups of the flow pattern in the DTC. They are spiral nonvortex, spiral vortex, and unending spiral pattern. The flow structure inside the DTC is formed by these three flow patterns. For each inlet-outlet orientation, the the DTC produces a dominantly tangential flow. The flow structure in the TJC is characterized by the helical jet pattern and by the wavy axial jet pattern. The structure of the helical jet is determined by the initial tangential intensity $\left(\mathrm{I}_{\mathrm{IT}}\right)$ and the inlet aspect ratio $\left(\mathrm{R}_{\mathrm{IA}}\right)$. The $\mathrm{I}_{\mathrm{IT}}$ value influences the helical jet profile. The higher the IIT value, the higher the helical jet number and the smaller the helical jet size. The inlet aspect ratio $\left(\mathrm{R}_{\mathrm{IA}}\right)$ also influences the tangential velocity profile. The higher the $\mathrm{R}_{\mathrm{IA}}$ value, the higher the tangential velocity will be. There is no back flow phenomenon (recirculation flow) in the TJC. The flow structure is identified as a non-vortex flow pattern. 


\section{ACKNOWLEDGEMENTS}

We would like to thank to Ministry of Research, Technology and Higher Education of Indonesia for the awarded research fund to this research on the decentralization research scheme.

\section{REFERENCES}

[1] Hoekstra AJ, Derksen JJ, Van Den Akker HE. An experimental and numerical study of turbulent swirling flow in gas cyclones. Chem Eng Sci. 1999; 54: 20552065.

[2] Obermair S, Woisetschlager J, Staudinger G. Investigation of the flow pattern in different dust outlet geometries of a gas cyclone by laser doppler anemometry. Powder Technol. 2003; 138: 239- 251.

[3] Ko J. Numerical modelling of highly swirling flows in a cylindrical through-flow hydrocyclone, Thesis. Royal Institute of Technology, Stockholm, Sweden. 2005.

[4] Houben JJH, Weiss C, Brunnmair E, Pirker S. CFD simulations of pressure drop and velocity field in a cyclone separator with central vortex stabilization rod. Journal of Applied Fluid Mechanics. 2016; 9: 487-499.

[5] Gupta A, Kumar R. Three dimensional turbulent swirling flow in a cylinder: Experiments and computation. Int J Heat Fluid Flow. 2007; 28: 249-261.

[6] Hreiz R, Gentric C, Midoux N. Numerical investigation of swirling flow in cylindrical cyclones numerical investigation of swirling flow in cylindrical cyclones. Chem Eng Res and Des. 2011; 89: 2521-2539.

[7] Hreiz R, Gentric C, Midoux N, Lainé R, Fünfschilling D. Hydrodynamic sand velocity measurements in gas-liquid swirling flows in cylindrical cyclones. Chem Eng Res and Des. 2014; 92: 2231-2246.

[8] Chen J, Haynes BS, Fletcher DF. Numerical and experimental study of tangensially injected swirling pipe flows. $2^{\text {nd }}$ International Conference on CFD in the Minerals and Process Industries. Melbourne, Australia. 1999.

[9] Nemoda S, Bakic V, Oka S, Zivkovic G, Crnomarkavic N. Experimental and numerical investigation of gaseous fuel combustion in swirl chamber. Int $\mathbf{J}$ Heat Mass Transfer. 2005; 48: 4623-4632.

[10] Escudier MP, Nickson AK, Poole RJ. Influent of outlet geometri on strongly swirling turbulent flow through a circular tube. Phys of Fluids. 2006; 18: 1-18.

[11] Escue A, Cui J. Comparison of turbulence models in simulating swirling pipe flows. Appl math model. 2010; 34: 2840-2849.

[12] Vazquez JAR. A computational fluid dynamics investigation of turbulent swirling burner. Thesis. University of Zaragoza, Zaragoza, Spain. 2012.

[13] Bourgouin JF, Moeck J, Durox D, Schuller T, Candel S. Sensitivity of swirling flows to small changes in the swirler geometry. CR Mecanique. 2013; 341.

[14] Reda E, Zulkifli R. Harun Z. Large eddy simulation of wind flow through an urban environment in its full-scale wind tunnel models. Journal of Mechanical Engineering and Sciences. 2017; 11: 2665-2678.

[15] Galvan S, Reggio M, Guibault F. Assesment study of k- $\varepsilon$ turbulence models and nearwall modeling for steady state swirling flow analysis in draft tube using fluent. Engineering Applications of Computational Fluid Mechanics. 2001; 5: 459-478. 
[16] Shamam KK, Birouk M. Assessment of the performances of rans models for simulating swirling. The Open Aerospace Engineering Journal. 2008; 1: 8-27.

[17] El-Behery SM, Hamed MH. A comparative study of turbulence models performance for turbulent flow in a planar asymmetric diffuser. World Academy of Science, Engineering and Technology. 2009; 53: 769-780.

[18] Aroussi A, Kucukgokoglan S, Pickering SJ, Menacer M. Evaluation of four turbulence models in the interaction of multi burners swirling flows. $4^{\text {th }}$ International Conference On Multiphase Flow. New Orleans, Louisiana, USA. 2011.

[19] Liu C, Liu C, Ma W. RANS detached eddy simulation and large eddy simulation of internal Torque converters flows: A comparative study. Engineering Applications of Computational Fluid Mechanics. 2015; 9: 114-125.

[20] Ansys Inc. Ansys documentation: Solver theory. United States: Canonsburg; 2013.

[21] Bindar Y. Computational engineering on turbulent multi-dimensional flows (in Indonesian language), First Edition. Bandung: ITB Press; 2017.

[22] Launder BE, Spalding DB. Mathematical models of turbulence. London: Academic Press. 1972.

[23] Launder BE, Reece GJ, Rodi W. Progress in the development of a Reynolds-stress turbulence closure. J Fluid Mech. 1975; 68: 537-566.

[24] Patankar SV. Numerical heat transfer and fluid flow. Washington DC: Hemisphere; 1980.

[25] Chung TJ. Computational fluid dynamics. New York: Cambridge University Press; 2010.

[26] Xia B, Sun DW. Applications of computational fluid dynamics (CFD) in the food industry. Comput Electron Agr. 2002; 34: 5-24.

[27] Bindar Y. Geometry effect investigation on a conical chamber with porous media boundary condition using computational fluid dynamic (CFD) technique. ITB J. Eng. Sci. 2009; 42: 97-110.

[28] Elsayed K, Lacor C. Optimization of the cyclone separator geometry for minimum pressure drop using mathematical models and cfd simulations. Chem Eng Sci. 2010; 65: 6048-6058.

[29] Lopes GC, Rosa LM, Mori M, Nunhez JR, Martignoni WP. CFD study of industrial FCC risers: the effect of outlet configurations on hydrodynamics and reactions. Int J Chem Eng. 2012; 2012: 1-16.

[30] Talbi K, Nemouchi Z, Belghar N. An experimental study and a numerical simulation of the turbulent flow under the vortex finder of a cyclone separator. Journal of Applied Fluid Mechanics. 2011; 4: 69-75.

[31] Riahi A. Turbulent swirling flow in short cylindrical chambers. Thesis. University of British Columbia, Van Couver, Canada. 1990.

[32] Jakirlic S, Hanjalic K, Tropea C. Modelling rotating and swirling turbulent flows: A perpetual challenge. AIAA J. 2002; 40: 1984-1996.

[33] Noor MM, Wandel AP, Talal Y. Design and development of mild combustion burner. Journal of Mechanical Engineering and Sciences. 2013; 5: 662-676.

[34] Treedet W, Suntivarakorn R. Effect of various inlet geometries on swirling flow in can combustor. Journal of Mechanical Engineering and Sciences. 2018;12: 3712-3723.

[35] Wang L, Parnell CB, Shaw BW, Lacey RE. A theoritical approach for predicting number of turns and cylone pressure drop. ASABE. 2006; 49: 491-503. 
Three dimensional cyclonic turbulent flow structures at various geometries, inlet-outlet orientations and operating conditions

[36] Hing YK, Chin WM, Heikal MR. Numerical and experimental determination of wavy fin-tube shape factor. Journal of Mechanical Engineering and Sciences. 2014; 6: 889-900. 